NBER WORKING PAPER SERIES

\title{
WHAT IS THE ADDED VALUE OF PRESCHOOL FOR POOR CHILDREN? LONG-TERM AND INTERGENERATIONAL IMPACTS AND INTERACTIONS WITH AN INFANT HEALTH INTERVENTION
}

\author{
Maya Rossin-Slater \\ Miriam Wüst \\ Working Paper 22700 \\ http://www.nber.org/papers/w22700 \\ NATIONAL BUREAU OF ECONOMIC RESEARCH \\ 1050 Massachusetts Avenue \\ Cambridge, MA 02138
}

September 2016, Revised June 2019

This paper was previously circulated under the title "Are Different Early Investments Complements or Substitutes? Long-Run and Intergenerational Evidence from Denmark". We thank Hoyt Bleakley, Gabriella Conti, Rasmus Landers $\varnothing$, Shelly Lundberg, Michael MuellerSmith, Diane Schanzenbach, Jeffrey Smith, and seminar participants at UC Santa Barbara, the University of Iowa, the University of Michigan, the University of Copenhagen, the University of Southern Denmark, Lund University, Santa Clara University, Stanford University, Statistics Norway, the University of Virginia, USC CESR, the "Early Childhood Inequality Workshop" (Nuremberg), the NBER Summer Institute, the All- California Labor Economics Conference, the ASSA meetings, and the NBER Cohort Studies meeting for helpful comments. We are grateful to Peder Dam and the "DigDag" project for invaluable help with the data on Denmark's historical administrative structure. Ida Lykke Kristiansen provided excellent research assistance. The Danish Data Archive provided the data from the "Statistical Commune Data Archive." We gratefully acknowledge financial support from the Danish Council for Independent Research (grant \# 4003-00007). The views expressed herein are those of the authors and do not necessarily reflect the views of the National Bureau of Economic Research.

NBER working papers are circulated for discussion and comment purposes. They have not been peer-reviewed or been subject to the review by the NBER Board of Directors that accompanies official NBER publications.

(C) 2016 by Maya Rossin-Slater and Miriam Wüst. All rights reserved. Short sections of text, not to exceed two paragraphs, may be quoted without explicit permission provided that full credit, including $\odot$ notice, is given to the source. 
What is the Added Value of Preschool for Poor Children? Long-Term and Intergenerational Impacts and Interactions with an Infant Health Intervention

Maya Rossin-Slater and Miriam Wüst

NBER Working Paper No. 22700

September 2016, Revised June 2019

JEL No. H51,H53,I18,I3,J13

\title{
ABSTRACT
}

We study the impact of preschool targeted at children from low-income families over the life cycle and across generations, and examine its interaction with an infant health intervention. Using Danish administrative data with variation in the timing of program implementation over 1933-1960, we find lasting benefits of access to preschool on adult educational attainment, earnings, and survival beyond age 65. We also show that children of women exposed to preschool obtain more education by age 25 . However, exposure to nurse home visiting in infancy reduces the added value of preschool. This result implies that the programs serve as partial substitutes.

\author{
Maya Rossin-Slater \\ Department of Health Research and Policy \\ Stanford University School of Medicine \\ 259 Campus Drive \\ Redwood Building T101C \\ Stanford, CA 94305-5405 \\ and NBER \\ mrossin@stanford.edu \\ Miriam Wüst \\ University of Copenhagen \\ miriam.w@econ.ku.dk
}




\section{Introduction}

A large body of research demonstrates that individuals' early life circumstances influence their long-term well-being (Almond et al., 2017; Almond and Currie, 2011; Barker, 1990). This evidence, combined with the fact that most parents in developed countries work in the labor market when their children are young, highlights the potential value of investment in public preschool programs, especially for low-income children with limited alternative care options. While a robust literature examines the impacts of American preschool programs targeting poor children on their outcomes during childhood and into mid-adulthood, ${ }^{1}$ we know less about effects on human capital and health in other settings, further in the life cycle or in the next generation. Moreover, existing evaluations of public preschools do not account for possible interactions with other early childhood programs. As programs for poor families often have overlapping eligibility criteria-meaning that low-income children are likely to be exposed to multiple interventions in early life evidence on interactions would not only inform discussions about public spending and program design, but also shed light on predictions of theoretical models of human capital formation that posit dynamic complementarities between multiple investments at different stages of childhood and across different parameters of the child production function (Cunha and Heckman, 2007; Heckman and Masterov, 2007; Heckman and Mosso, 2014).

This paper attempts to fill these gaps by using large-scale population-level data to study the rollout of the first Danish public preschool program for poor children. In addition to allowing us to measure the health and human capital outcomes of exposed cohorts through age 65 and the outcomes of their children through age 25, the Danish historical setting provides a unique opportunity to examine the added value of preschool for a population that received an earlier health intervention in infancy. Preschool access was expanded over the same time period as a nurse home visiting (NHV) program for new mothers and infants. Existing research shows that NHV had short- and long-term health benefits (Wüst, 2012; Hjort et al., 2017; Wüst et al., 2018), with similar evidence from comparable programs in

\footnotetext{
${ }^{1}$ For research on U.S.-based preschool programs for poor children, including Head Start, Perry Preschool, and the Carolina Abecedarian Project, see: Currie and Thomas (1995); Garces et al. (2002); Masse and Barnett (2002); Schweinhart et al. (2005); Belfield et al. (2006); Ludwig and Miller (2007); Anderson (2008); Deming (2009); Heckman et al. (2010a,b); Carneiro and Ginja (2014); Campbell et al. (2014); García et al. (2016); De Haan and Leuven (forthcoming); Garcia et al. (2018); Thompson (2017); Bailey et al. (2018); Heckman and Karapakula (2019b). Outside the United States, there is some evidence on the mediumterm effects of access to more recently expanded universal preschools in Norway and Denmark, which enroll children from all socio-economic backgrounds (Havnes and Mogstad, 2011, 2015; Datta Gupta and Simonsen, 2016). The fact that the benefits of universal programs are often largest for disadvantaged children (Cascio, 2015) raises the question of whether programs explicitly targeting poor children could have even larger returns in these settings.
} 
Norway and Sweden (Bhalotra et al., 2015; Bütikofer et al., 2014). Important to our analysis is the fact that some municipalities implemented the NHV program before the preschool program, while others implemented the preschool program before the NHV program, and the two rollouts were independent of each other. As such, we have found a rare situation where "lightning strikes twice" in observational data (Almond and Mazumder, 2013), making us well-positioned to identify interactions across two early childhood programs, and examine whether they serve as complements or substitutes to one another.

The Danish preschool program that we study primarily served poor children ages 3 through 7, and entailed a significant improvement in their care environment through its health and early education components. Although individual municipalities operated their own preschools, they were required to go through a formal approval process to receive funding from the national government. To receive approval, the preschool needed to predominantly enroll children from poor households, meet requirements for adequate sanitation and child nutrition, and have regulated service hours. Approval was granted to center directors and the accompanying center board for a specific number of slots. This process ensured that preschools had qualified management and adequate facilities for young children. Additionally, the national government incentivized cooperation between preschools and local health care providers to offer health check-ups to the children. Further, a national early education movement created uniformity in pedagogy across approved preschools; curricula were based on the principles of influential educators, including Friedrich Fröbel and Maria Montessori. As young children of poor working mothers during this time period would have otherwise been watched by older siblings, relatives, or neighbors, public preschools provided a substantially higher quality and more standardized level of care. ${ }^{2}$

Our analysis combines historical program data and individual-level administrative data on the population of Danish individuals born in 1930-1957 and their children. We exploit policy variation in the expansion of government-approved and regulated preschools across 138 Danish municipalities that established such a preschool by 1960 (and that account for approximately 53 percent of the Danish population born during this time period), and estimate difference-in-difference models. We take multiple steps to address the central threat to identification in our setting: endogeneity in the rollout of approved preschools. Specifically, compared to rural municipalities, urban areas implemented the program earlier and are more likely to be among the "always-implementers" in our sample (i.e., municipalities that had

\footnotetext{
${ }^{2}$ Other than the preschool program, there was limited public support for working parents, especially when compared to the Scandinavian policy landscape in more recent decades. The period that we study is prior to the large-scale expansion of the Danish social safety net in the 1960s and 70s. For instance, Denmark introduced universal paid maternity leave of 14 weeks in 1960 (DICE Database, 2015) and universal health insurance in 1973 (Vallgårda et al., 2001).
} 
a preschool by 1933, the first year of potential preschool enrollment for the oldest cohort in our data). Since urban and rural areas differ on a range of observable characteristics, it is not surprising that geographical, political, and social factors measured in the early 1920s correlate with the timing of preschool approval. Thus, our preferred specification includes municipality time-varying controls and county-specific linear trends (in addition to standard cohort and municipality fixed effects). Moreover, we assess the robustness of our main findings to: (i) using an event-study model that only includes municipalities that change treatment status during our sample period and omits the always-implementers, and (ii) only using data from urban municipalities that display more arbitrary variation in treatment timing.

We find that access to a government-approved preschool by age 3 improves long-term human capital outcomes and longevity. We document a 0.024 standard deviation (SD) increase in a summary human capital index, driven by a 0.1 year rise in the average number of years of schooling, a 1.7 percentage point increase in the likelihood of obtaining more than a compulsory education, and a 1.7 percent higher average wage income over the ages of 30 to 60 . We also show that access to preschool at age 3 raises the likelihood of survival beyond age 65 by 0.7 percentage points. Scaled by the approximate rate of preschool enrollment of around 10 percent, our estimates translate into substantial benefits for treated individuals, which are comparable to estimates of effects of preschool programs targeting low-income children in the U.S., including Head Start, Perry Preschool, and the Carolina Abecedarian Project (see, e.g., Garces et al., 2002; Heckman et al., 2010a; García et al., 2016; Thompson, 2017; Bailey et al., 2018; Garcia et al., 2018; Heckman and Karapakula, 2019b).

Next, we break new ground by using large-scale administrative data to document an intergenerational impact of preschool - we find that children of women with access to a government-approved preschool by age 3 are 0.9 percentage points more likely to have completed more than a compulsory education by age 25 . This result contributes to a vast literature on intergenerational correlations in measures of socio-economic status including education and income in both the U.S. and Europe (e.g.: Solon, 1992; Bauer and Riphahn, 2004; Hertz et al., 2007; Lee and Solon, 2009; Black et al., 2009; Black and Devereux, 2011; Chetty et al., 2014). The existing literature suggests that the correlation between parents' and children's years of schooling in Denmark for this time period is around 0.3 (Hertz et al., 2007), which is remarkably similar to the 0.28 intergenerational transmission coefficient we obtain by dividing our second generation coefficient for years of schooling by the respective first generation coefficient. ${ }^{3}$ Our quasi-experimental estimate of the intergenerational

\footnotetext{
${ }^{3}$ If we divide the coefficients for the probability of having more than compulsory education, we obtain an intergenerational transmission coefficient of 0.53 . However, it is difficult to compare this coefficient to other
} 
transmission coefficient relates to two concurrent studies that also examine the impacts of interventions in one generation on the adult outcomes of the next generation. ${ }^{4}$ Barr and Gibbs (2017) analyze Head Start, the major public preschool program in the United States, using variation in program rollout and an analysis sample of approximately 1,700 individuals from the National Longitudinal Survey of Youth (NLSY). They show that children of mothers who were exposed to the Head Start program have higher educational attainment and lower incidence of risky behaviors than children of non-exposed mothers. Heckman and Karapakula (2019a) explore the intergenerational effects of the experimental Perry Preschool program using data on 80 children of 112 experiment participants. They find that children of treated participants have fewer school suspensions, higher education and employment levels, and lower crime rates than children of control subjects. Our estimate of the intergenerational effect of preschool, which is based on a much larger administrative data set in a setting outside the United States, complements this evidence.

Finally, we find a negative interaction effect between access to preschool and NHV: For the human capital index, access to NHV reduces the positive impact of preschool by 74 percent. We also find negative (but statistically insignificant) interaction coefficients when we consider survival beyond age 65 and the education of the next generation as outcomes. These results, which show that the marginal benefit of preschool is lower for individuals exposed to NHV at birth, are consistent with other studies documenting that the impacts of preschool are largest for the least advantaged children (Bitler et al., 2014; Havnes and Mogstad, 2011, 2015; Cascio, 2015; Herbst, 2017; Thompson, 2017). However, unlike prior work, we identify heterogeneous returns to preschool across individuals who differ in their early life environments due to a program-driven source of variation: Our estimates imply that high quality preschool can compensate for initial disadvantages in health, as measured by a lack of NHV. The NHV program provided parents of infants with education about nutrition, parent-child interactions, and the overall home environment, and facilitated referrals to health care professionals. Thus, the preschool environment-which incorporated some similar health-related elements but at slightly older ages - constituted a less significant treatment for cohorts already exposed to NHV. Our conjecture that the health component of preschool

estimates because intergenerational correlations in education are typically estimated using years of schooling as the outcome. In our data, the raw correlation between the likelihood of a mother completing more than a compulsory education and her child completing more than a compulsory education is 0.2 , and the estimate falls to 0.17 when we include year of birth indicators for mothers and children to account for cohort effects. It is possible that we underestimate the correlation between maternal and child educational attainment as some of the child cohorts in our sample are too young to have completed their schooling.

${ }^{4}$ In related work, East et al. (2017) show that early childhood access to Medicaid - the main public health insurance program for low-income families in the U.S. - has positive impacts on the birth outcomes of the next generation. When it comes to adverse in utero shocks, Black et al. (2013) use Norwegian data to show that children of individuals who were exposed to radiation in utero have lower IQ scores. 
is an important mechanism for its long-term and intergenerational effects on cohorts without prior exposure to NHV is consistent with other studies on targeted preschools in the U.S. (Currie and Thomas, 1995; Ludwig and Miller, 2007; Carneiro and Ginja, 2014; Campbell et al., 2014; Bailey et al., 2018), which posit that health screenings, referrals, and nutritious meals are key components driving the effects of preschool on child and adult well-being.

Our finding of a negative interaction effect from exposure to two early life health-related programs further contributes to our understanding of human capital formation. Recent influential theoretical models propose dynamic complementarities between investments at different stages of childhood and across different parameters of the child production function (Cunha and Heckman, 2007; Heckman and Masterov, 2007; Heckman and Mosso, 2014). While there is some support for the dynamic complementarities hypothesis from research documenting that the effects of preschool interventions are larger for those with higher measures of initial endowments (Aizer and Cunha, 2012; Heckman et al., 2013), other differences between children with lower and higher initial skills may complicate this interpretation. In our study, we do not observe the full set of investments in children, making us unable to assess the relative importance of parental investment responses to public policies (as in, e.g., Greaves et al., 2019). However, we contribute new causal empirical evidence on the interaction between public investments by overlaying two sources of plausibly exogenous variation. Our approach is similar to a few other recent studies that examine different types of investments. Two studies find complementarities in educational investments during school ages in the U.S. (Johnson and Jackson, Forthcoming; Gilraine, 2017), while several other papers find either zero or sizeable negative interaction effects between a variety of childhood investments in other settings including Bangladesh, Mexico, and Romania (Gunnsteinsson et al., 2014; Adhvaryu et al., 2015; Malamud et al., 2016). Our results demonstrate the presence of substitutability in health-related public investments in early childhood.

\section{The Danish Preschool Expansion}

We study the introduction and expansion of publicly-funded and centrally regulated preschools for poor Danish children between 1933 and 1960. Unfortunately, we do not have detailed information on each municipality's implementation process or on individual preschools' characteristics (e.g., the physical facilities or teacher credentials). However, we rely on the best available historical sources to argue that the introduction of government-regulated preschools, in combination with a nationwide focus on teacher quality and pedagogy, represented a substantial improvement in the quality of care provided to poor young children during this time period. Additionally, while Danish society undoubtedly changed in a vari- 
ety of ways during the almost 30-year period that we study, the main features of preschools and the underlying early education principles were remarkably stable. After 1960, Denmark (along with other Scandinavian countries such as Norway) shifted its policy agenda to expanding universal access to preschools for children from all backgrounds. But universal preschools played a limited role during the earlier period that we analyze, and we therefore believe that our results are most comparable to those from studies of preschool programs targeting disadvantaged children.

In what follows, we first discuss the government's role in ensuring quality standards across preschools, and then discuss two central components of the preschool environment: health and early education.

Government involvement in preschools. The earliest Danish preschools in the 19th century ("asylums") were privately operated by philanthropic organizations (e.g., churches) and completely unregulated. As labor markets and family structures changed at the turn of the century, Danish political parties began to nearly unanimously support regulations and funding mechanisms that became the basis of the public preschool expansion (Kristensen and Bayer, 2015). In 1919, the Danish parliament enacted its first law on "preventative child services," with a goal of providing financial support for targeted preschools that enrolled poor preschool-aged children of working mothers.

Under the law, new and existing preschools could apply for government subsidies to cover ongoing expenses (e.g., staff wages or rent) or to establish, improve, or expand their facilities (Skjernbæk, various years). ${ }^{5}$ To be eligible for a subsidy, a preschool had to obtain approval from the national government by meeting a series of requirements. Approved preschools had to: (1) provide adequate sanitation at the facility, (2) charge parents fees that could cover food and milk provided to children (very poor parents could apply for an exemption), (3) have a qualified preschool center director, staff, and a board of members with expertise on children, (4) be open at least four hours each working day, and (5) predominantly enroll children from poor families. ${ }^{6}$ Preschools could also apply to the national government for

\footnotetext{
${ }^{5}$ The subsidy amounts and structure varied over time. They initially covered 30 percent for expenses related to daily operations, and were around 50 percent for expenses related to the establishment or improvement/expansion of existing institutions. They were increased over the 1940s and 50s. Additionally, from the 1940s onward, municipal governments became involved in financing: If a municipality ran a preschool or subsidized a private preschool for at least 30 percent of its daily expenses, the subsidy from the national government was increased to 40 percent. Since these subsidy reforms were implemented at the national level, we do not exploit them in our analysis, which relies on the municipality-level variation.

${ }^{6}$ From 1949 onward, preschools that did not predominantly serve poor families could receive smaller subsidies from the national and municipal governments (for a total of around 35 percent of all costs) (Skjernbæk, various years; Kristensen and Bayer, 2015). However, with a limited number of preschools and long wait lists, non-poor children rarely enrolled prior to the 1960s. A preschool could either be run by a municipality government (which employed staff with expertise on children) or by a private organization with a
} 
reimbursement of check-ups and vaccinations by local health care providers. ${ }^{7}$

Child health at preschool. The above discussion makes clear that early Danish public preschools incorporated a significant health-related treatment for disadvantaged children. The idea that preschools influence child health (in addition to offering early education) is not unique to historical Denmark. In fact, studies show that a substantial part of the benefit of Head Start - the largest public preschool program for low-income children in the U.S. - can be attributed to its nutritional and medical services (Currie and Thomas, 1995; Ludwig and Miller, 2007; Carneiro and Ginja, 2014; Bailey et al., 2018). Similarly, the much smaller scale intensive Abecedarian Project intervention featured nutritional and health care components, and has been shown to have positive effects on metabolic and cardiovascular health measures for adults in their 30s (Campbell et al., 2014). In our setting, poor children's health was likely impacted through access to regular nutritious meals, improved sanitary conditions, and the monitoring of children's health by preschool staff and local health care providers.

Early education. The introduction of central government regulations and public financing of preschools was accompanied by a broader early education movement in Denmark. This movement was mainly inspired by the pedagogical principles of Friedrich Fröbel and Maria Montessori, and had a significant impact on preschool quality through its focus on preschool teachers' training: Over the period we study, Danish teachers who had previously trained abroad started multiple educational programs for preschool staff (Kristensen and Bayer, 2015, p.167). The educational program of the Fröbel institute in Copenhagen began in 1904, while Montessori-inspired teacher training programs were introduced in the mid-1920s. By 1945, Denmark had at least five educational programs for preschool teachers, who were typically trained for two years. In the years 1935-1950, those institutions trained a total of 1,566 preschool teachers (Kristensen and Bayer, 2015). By 1953, 72 percent of preschool staff were trained (Kristensen and Bayer, 2015, p. 277). Trained preschool teachers also formed unions, which lobbied for adequate educational programs and higher wages for preschool

board of members with expertise on children (e.g., a pediatrician, a teacher, etc.). In the early years of the preschool expansion, the majority of preschools were run by private non-profit organizations, while municipal preschools became more common throughout the expansion period (Pedersen et al., 2011b). Preschools were allowed to be closed for up to four weeks during the summer and a total of two weeks around holidays such as Christmas or Easter. Preschool approval was always granted to a specific center head and for a specified number of slots at the center.

${ }^{7}$ In the 1930-1960 period, vaccines against the following diseases were available to all children through the national vaccination program: smallpox (mandatory since 1931), diphteria (1943), tuberculosis (1946), tetanus (1949), and polio (1955). The vaccination program was expanded by the Danish National Board of Health and the Serum Institute. See http://www.ssi.dk/Vaccination/Boernevaccination/ Sygdomsforekomst $\% 20$ foer $\% 20$ og $\% 20$ efter $\% 20$ vaccination. aspx for more information. 
staff. $^{8}$

In sum, government co-funded and regulated preschools from the 1920s onward provided poor Danish children ages 3 through 7 with higher quality of care and early education, nutrition, and health services than they would have otherwise received. At the time, poor mothers, who had to work outside the home, would typically leave small children alone at home, under the supervision of older siblings, or in the care of other relatives or neighbors (Pedersen et al., 2011a, p728). ${ }^{9}$ As we show below, there was substantial variation across Danish municipalities in the timing of the first government approval of a preschool. We exploit this variation in our main analysis and discuss the identifying assumptions in detail in Sections 4 and 5.

\section{Data and Sample}

We merge data from several sources. First, we use information on the geographical and administrative structure of Denmark over 1920-1955. Second, we collect data on the establishment and government approval of preschools and the implementation of the Nurse Home Visiting program. Third, we compile a unique set of historical municipality control variables. Fourth, we use administrative individual-level data on the adult outcomes of cohorts born in 1930-1957 and their children.

Data on Denmark's historical administrative structure. We use data on several historical Danish administrative entities, including parishes and municipalities, from the "Digital Atlas of the Danish Historical and Administrative Geography (DigDag)". ${ }^{10}$ As births in Denmark are registered at the parish level, we use these data together with information on individuals' parishes of birth in our long-run outcomes data to merge individuals to their municipalities of birth (and thus to assign individuals' treatment status).

Data on preschools. We have collected data on all approved Danish preschools that existed over the 1921-1960 period from nine books published in 1921, 1924, 1927, 1936, 1942,

\footnotetext{
${ }^{8}$ Unfortunately, we have no time series data on the share of trained staff. A formal state regulation of preschool education programs was introduced in 1953. The largest union was established in 1932 ("Dansk Børnehaveråd").

${ }^{9}$ According to available estimates, the Danish female labor force participation rate was between 30 and 40 percent during the first half of the 20th century, (Olivetti, 2013).

${ }^{10}$ For more information, please see: www.digdag.dk. In the period that we study, Denmark consisted of over 1,300 municipalities that were heterogeneous in their size, population density, and composition. Each municipality contained one or more parishes. The vast majority of rural municipalities only had one parish each. The 86 urban municipalities - also known as "Købstader," or market towns - consisted of multiple parishes.
} 
1946, 1950, 1956 and 1960 (Skjernbæk, various years). ${ }^{11}$ These data contain information on the preschool's first registered exact address (i.e., we can assign preschools to municipalities), the year of establishment and the year of government approval, and the number of children registered in each of the given nine years. As noted above, in our main analysis, we use variation in the timing of approval of preschools. ${ }^{12}$

Out of the 1,354 Danish municipalities that existed between 1930 and 1960, 138 had at least one approved preschool by 1960. Figure 1a depicts these municipalities in a map of Denmark (using its 1950 administrative structure). As we show in Table 1, the municipalities without approved preschools are mostly very small and rural; the 138 municipalities with at least one approved preschool had ten times higher average population counts in 1930 than the other municipalities. Individuals born in municipalities with at least one approved preschool account for 53 percent of the population we observe in our administrative individual-level data (described below). Table 1 also shows that there are substantial differences between the municipalities with and without approved preschools by 1960 in terms of politics, average income, and industrialization. Therefore, we limit all of our analysis to the more homogeneous sample of 138 municipalities that ever had a government-approved preschool by 1960 . These municipalities are still fairly small entities, with a median population of 4,606 in 1930 .

Figure 1b shows the evolution of preschools in these 138 municipalities. We begin the graph in 1933 as our oldest cohorts are born in 1930 and we measure preschool exposure at age 3 . In 1933, only about 20 percent of municipalities in our sample had at least one approved preschool, whereas by 1960, all of them did. Most municipalities only ever have one approved preschool - the median number of preschools per municipality is one, while the 75th percentile is two. Only 18 municipalities in our data ever had more than five approved preschools. Thus, most of our analysis uses variation in the initial preschool approval (changing from zero to one approved preschool).

Data on the Nurse Home Visiting program. In 1937, the Danish parliament passed a bill that regulated the content and funding of a Nurse Home Visiting program serving all families with newborns. The Danish National Board of Health (DNBH) had developed the

\footnotetext{
${ }^{11}$ The majority of preschools served children starting at age 3 and through the year when they turned 7 (i.e., the school starting age). A minority of preschools in our data also accepted younger children.

${ }^{12}$ By studying the impacts of preschool approval rather than establishment, we can estimate the impacts of access to a regulated, high quality preschool (and not just any preschool). In practice, however, the years of establishment and approval are the same for many preschools. Our results are similar if we use the year of establishment to assign treatment (see brief discussion in Section 5). Additionally, we use the original address of the preschool even though some preschools move. Usually, preschools only moved within the same municipality, e.g., to get more space. The records for the total number of slots per preschool are unfortunately incomplete; we only have data on the number of enrolled children in each preschool in each of the nine years of publications.
} 
program to address the relatively high infant mortality rate of around 6.5 percent at the time (DNBH, various years). As a considerable share of infant mortality was due to preventable causes - among them, infectious diseases caused by the improper treatment of cows' milkthe DNBH designed the program to promote breastfeeding and a safe home environment. While the DNBH centrally initiated the program and the Danish government co-funded 50 percent of its expenses, implementation was under municipal discretion. Variation in the timing of program implementation across municipalities largely stemmed from the lengthy accreditation process at the DNBH and differences in the preferences of local general practitioners, who in some places promoted the initiation of NHV but in other places opposed it as it (Buus, 2001). Once established, NHV assigned visits of trained nurses to all newborns and their mothers approximately ten times in the first year of life. Nurses provided information on infant care, monitored infants' development, and referred ill infants to doctors for treatment. Appendix B provides additional institutional details about the program, a discussion of the previous research, and a replication of the main results from Hjort et al. (2017) on the long-term health impacts of NHV using our preschool analysis sample.

We use information on the date of NHV program approval from the DNBH in the period 1937-1949 from records stored in the Danish National Archives (for further details see Hjort et al., 2017). Approval was only granted to municipalities with sufficient coverage, i.e., if the number of nurses matched the estimated demand (number of infants). Thus, we create an indicator for an approved program being in place. For the 28 municipalities in our sample that did not implement an NHV program by 1949, we assign a (less precise) treatment date using Skjernbæk (various years), which contain lists of NHV-treated municipalities. We assign either (i) the year of the previous publication to municipalities that are listed as treated in a given publication or (ii) a "never treated" status for municipalities that are not featured on these lists. We test the robustness of our main results to dropping cohorts and municipalities with less precise NHV data.

Data on municipality-level demographics, live births, and infant deaths. The data on municipality-level characteristics for the time period that we study is quite limited. The Statistical Commune Data Archive (Danish Data Archive) contains voting records from national and local elections and data from the quinquennial censuses. From these data we use information on the share of voters for different parties, municipality population size, and demographic information including the share of females, the shares of workers in the industrial and agricultural sectors, the shares of the population paying income and property taxes, the share of the population in urban areas, and mean taxable income. Since these variables exist only for a subset of our sample years (election and census years), we interpolate 
these data for our analysis. ${ }^{13}$

Additionally, we use data on the annual number of live births and infant deaths that are only available for urban municipalities in years 1933-1950 (DNBH, 1933-1950) in supplemental analyses on program coverage and potential endogenous mortality. In the urban municipalities in our ever-implementing sample, the median number of live births over 19331950 was 146.

Individual-level administrative data. We use administrative population register data for the years 1980-2012 for cohorts born in 1930-1957. As outcomes, we consider several measures of human capital (around age 50) and health (survival past different ages, hospital admissions, and diagnoses). Moreover, we can link first-generation women from the 19351957 cohorts to their children (Pedersen et al., 2006). When analyzing intergenerational outcomes, we focus on these women's oldest children, whom we can observe in the register data at age 25 (child cohorts born in 1955-1987). We focus on several measures of the children's education attainment by age $25{ }^{14}$

Sample construction and selection. As noted above, we limit our sample to individuals born in Denmark between 1930 and 1957. In addition, to be in our analysis, individuals must meet two criteria: First, the individual must have a valid code for her parish of birth that allows us to assign treatment status. Around 90 percent of Danish-born individuals in our outcome data have a valid parish of birth. ${ }^{15}$ Second, the individual must be observed in our post-1980 outcome data. Appendix C explores the possibility of selective mortality. We use data on live births and infant deaths to calculate the share of "missing individuals" across cohorts and test for correlation with preschool approval timing. We conclude that selective mortality prior to the age of observation in our data is unlikely to drive our results.

Our analysis sample of Danish-born individuals with valid parish codes consists of 1, 640,214 observations. When we limit to individuals born in the municipalities with an approved preschool by 1960, we are left with 880,708 observations.

\footnotetext{
${ }^{13}$ For the election data, we impute the share of voters in years between elections using the data from the most recent previous election. For the census data, we use a linear interpolation. Where necessary, we constrain our linear interpolation to values in the 0-100 range.

${ }^{14} \mathrm{We}$ have also estimated regressions using a sample of all children (observed at age 25 in our data period) of these mothers and not only the firstborns. Our results are similar and available in Appendix Table A.6. We discuss these results briefly in Section 5 .

${ }^{15}$ We omit individuals with errors in the parish of birth registration (such as those who are registered using post-1970 municipality information), individuals who were registered by religious minorities such as Catholics, and individuals with undocumented parish codes. Also, we omit individuals who were born in hospitals and therefore cannot be merged to their municipalities of birth. Hospital births for these cohorts were still rare only 5.5 percent of our sample - as home births were the norm in Denmark up until the 1960s.
} 


\section{Empirical Methods}

Our analysis exploits municipality $\times$ year variation in preschool approvals (and the NHV rollout) in a difference-in-difference design. To ease the computational burden and to estimate models at the level of variation, we take a two-step approach. First, we regress our outcome measures on all available pre-determined individual-level control variables (i.e., gender and month of birth indicators) as well as municipality $\times$ birth-year fixed effects. The municipality $\times$ birth-year fixed effects from this regression yield the conditional mean outcomes in each municipality $\times$ birth-year cohort, after controlling for the micro-covariates. Then, we collapse our data into 3, 862 municipality $\times$ birth-year-cells and use the conditional means as dependent variables in our regressions, which we weight by cell size. ${ }^{16}$

Our preferred model takes the following form:

$$
Y_{y m c}=\alpha_{0}+\alpha_{1} \mathbf{1}[\text { PreschoolAge } 3]_{y m}+\lambda_{m}+\gamma_{y}+\delta^{\prime} X_{y m}+\eta_{c} \times y+\epsilon_{y m c}
$$

for cohorts born in year $y$, municipality $m$, and county $c .{ }^{17} Y_{y m c}$ is an outcome of interest (conditional on the micro-covariates described above). $\mathbf{1}[\text { Preschool Age } 3]_{y m}$ is an indicator equal to one for cohorts that had at least one approved preschool in their municipality of birth at age 3, and zero otherwise. Thus these analyses assume that the municipality of birth is also the municipality of residence during early childhood. Unfortunately, we do not have data to measure mobility between birth and age 3 for the time period that we study. $\lambda_{m}$ are municipality fixed effects that account for time-invariant differences across municipalities, while $\gamma_{y}$ are birth year fixed effects that control for aggregate cohort trends. $X_{y m}$ is the vector of municipality time-varying controls described above, while $\eta_{c} \times y$ are county-specific linear trends. $\epsilon_{y m c}$ is the error term, and we use robust standard errors clustered by municipality. The key coefficient of interest, $\alpha_{1}$, identifies the effect of having a government-approved preschool in one's municipality of birth at age 3 on the outcome of interest.

To study interactions, we exploit municipality variation in preschool and NHV availability by birth year (recall, we measure access to preschool at age 3 and access to NHV in the birth year). As Appendix Figure A.1 shows, for cohorts born in 1930, about 80 percent of

\footnotetext{
${ }^{16}$ Donald and Lang (2007) show the asymptotic equivalence between this two-step group-means estimator and the micro-data counterpart. In Section 5 we show that our results are very similar when we estimate individual-level regressions instead. These types of two-step estimators have been used in many other papers (Shapiro, 2006; Angrist and Lavy, 2009; Albouy, 2009; Notowidigdo, 2011; Currie et al., 2015; Isen et al., 2017).

${ }^{17}$ Counties are the next-largest geographical entities after municipalities. In the period that we study, there are 23 counties and the capital Copenhagen. Each county contains between two and eight of the municipalities in our sample.
} 
municipalities did not have an approved preschool and NHV was not yet established. As the preschool and NHV programs expanded, the percentage of municipalities with both programs increased from zero for cohorts born in 1936 to 86 percent for cohorts born in 1957 in our sample. But, until 1948, between 20 and 50 percent of municipalities only had preschool and no NHV. In the late 1940s, nearly 10 percent of municipalities only had NHV and no approved preschool. Moreover, as we depict in Appendix Figure A.2, there is substantial variation in the difference in the number of years between preschool approval and NHV implementation.

Importantly, Table 2 shows that the two program rollouts are independent of one another. In column (1), we estimate a version of equation (1), using an indicator for having the NHV program at birth as the dependent variable. In column (2), we instead regress an indicator for having access to an approved preschool at age 3 on an indicator for having access to the NHV program at birth. In both specifications, we find little evidence for any statistically significant (or economically meaningful) relationship between the two programs. Moreover, Wüst (2012) and Hjort et al. (2017) provide evidence that the timing of the NHV program rollout is exogenous with respect to the outcomes in their analysis.

In sum, during our analysis time frame, there is quasi-random variation in program exposure: Some cohorts were exposed to neither preschool nor NHV, other cohorts were exposed to either only preschool or only NHV, while still others were exposed to both programs. We use this variation to estimate the following model:

$$
\begin{gathered}
Y_{y m c}=\beta_{0}+\beta_{1} \mathbf{1}[\text { PreschoolAge } 3]_{y m}+\beta_{2} \mathbf{1}[N H V]_{y m}+\beta_{3} \mathbf{1}[\text { PreschoolAge } 3]_{y m} \times \mathbf{1}[N H V]_{y m} \\
+\lambda_{m}+\gamma_{y}+\delta^{\prime} X_{y m}+\eta_{c} \times y+\epsilon_{y m c}
\end{gathered}
$$

Here, $\mathbf{1}[N H V]_{y m}$ is an indicator equal to one for cohorts that had the NHV program in their municipality in their year of birth and zero otherwise. All of the other variables and coefficients are the same as in equation (1). $\beta_{1}$ measures the impact of access to preschool at age 3 for cohorts without NHV, while $\beta_{2}$ measures the impact of access to NHV at birth for cohorts without preschool at age $3 . \beta_{3}$ identifies the interaction effect between the two programs.

Identifying assumptions. To identify the effects of access to preschool, we must rely on the assumption that the timing of preschool approvals is uncorrelated with unobserved time-varying municipality characteristics that also predict our long-run and intergenerational outcomes. The main threat to identification in our setting arises from the differences in economic development and political preferences between urban and rural municipalities. As 
already shown in Table 1, urban municipalities are heavily over-represented among those that establish an approved preschool by 1960. Even within the sample of ever-implementing municipalities that are included in our analysis, the urban/rural divide remains important. While all of our specifications include cohort and municipality fixed effects that account for aggregate trends in outcomes across cohorts and time-invariant municipality characteristics such as geography, we may still be concerned about omitted time-varying factors that correlate with preschool approval and long-term outcomes. ${ }^{18}$

To motivate our main specifications and robustness tests, we examine how pre-existing municipality characteristics predict the timing of preschool approval in urban and rural municipalities in Table 3. We estimate cross-sectional regressions where each observation is a municipality and include all available municipality characteristics measured in 1920-21. As outcomes, we consider an indicator for always having an approved preschool in the 19331960 period, an indicator for being an "early implementer" (approval before 1940), and the approval year of the first preschool among municipalities that approve during our sample period (1933-1960). As the table illustrates, the observed characteristics play some role in explaining the variation in the timing of the treatment initiation, especially in rural areas. While we cannot reject the null hypothesis that pre-characteristics are jointly insignificant in the urban areas at the $5 \%$ level, the individual point estimates are consistent with (expected) correlations between urbanicity and the expansion of the preschool program.

The results in Table 3 lead us to address the potential endogeneity in treatment in the following three ways: First, as mentioned above, we control for interpolated municipality characteristics and county-specific linear trends in our preferred specifications. ${ }^{19}$ Second, as Table 3 suggests that the variation in preschool approval appears to be more arbitrary

\footnotetext{
${ }^{18}$ The period that we study calls for a discussion of the role of World War II and its possible influence on our sources of variation. We would face a problem if the effect of the war varied across municipalities in a systematic way that correlated with the preschool and NHV expansions. Historical accounts make clear that Denmark - unlike many other European countries - was not very severely impacted by the German occupation between 1940 and 1945 (Pedersen, 2009; Poulsen, 2002). While coffee, tobacco and some other goods were rationed, there was nevertheless a stable supply of food for all Danish citizens (e.g., milk and bread were not rationed, see Poulsen, 2002). According to Pedersen (2009), "among all occupied countries, Denmark was the country with the smallest decrease in the standard of living and the country where everyday life was least impacted." (authors' translation, p. 404 in Pedersen, 2009). As such, we believe that World War II is not a confounding factor for our analysis. Moreover, we find no evidence of disruptions in the spread of preschools or NHV during the war years.

${ }^{19}$ We have also estimated models with separate linear trends across urban and rural areas. We present those results in Appendix Table A.7. We do not include municipality-specific linear trends because then we would only be able to identify effects that are deviations from these trends. We lack sufficient variation to do so because our treatment variable is linear in exposure (i.e., cohorts who are age 3 have one more year of exposure than cohorts who are age 4 at the time of preschool approval). Thus, we instead opt for including municipality time-varying characteristics (which are themselves linearly interpolated) and linear trends at the next largest level of geography (county).
} 
in urban than rural areas, we test the robustness of our results to only using urban municipalities. Third, we present results from event-study models. In addition to examining potential pre-trends in outcomes, these models rely only on variation within municipalities that change treatment during our sample time frame (i.e., they approve a preschool between 1934 and 1960), and thus provide evidence for our results being robust to the omission of very early adopting municipalities.

Unfortunately, we cannot link individuals who are exposed to preschool to their parents; i.e., we cannot examine whether access to preschool or NHV impacted the fertility patterns of the mothers of treated cohorts. To address the concern that the timing of preschool approval may be correlated with fertility decisions, we have used the available data on all births in urban municipalities in the years 1933-1950. As Appendix Table A.1 shows, we find no statistically significant correlation between the timing of preschool approval and the number of births in the subsequent three years. Finally, given that we do not observe family links for preschool-exposed cohorts and their parents, we cannot estimate maternal or family fixed effects models.

\section{Results}

\subsection{Effects of Preschool on the First and Second Generation}

We start by presenting results on the long-run effects of access to public preschool for poor children, as well as the intergenerational impacts on the children of mothers with preschool exposure. In the first generation, we focus on multiple measures of human capital and health as outcomes. While prior research has also examined the impacts of preschool on engagement in criminal activity, we lack data to study this other important domain of wellbeing. ${ }^{20}$

With respect to human capital of the first generation, we consider three main outcomes: years of schooling at age 50 (which adds up schooling across various educational programs), an indicator for having more than nine years of compulsory schooling at age 50, and the natural log of average wage income (in 2012 terms) for all ages observable between 30 and 60 in our data. To reduce concerns about multiple hypothesis testing, we also construct a human capital index: We standardize each of these three human capital measures by subtracting the control group mean and dividing by the control group standard deviation. Then we take an equally weighted average as in Kling et al. (2007), Deming (2009), and Hoynes et al. (2016) (among others). As the control group, we use all municipality $\times$ birth-

\footnotetext{
${ }^{20}$ We do not have access to Danish administrative conviction records data. Moreover, as the vast majority of convictions are observed in young adulthood, the available convictions data do not cover this period for our preschool-exposed cohorts.
} 
cohort cells without an approved preschool by age 3 in the sample of 138 ever-implementing municipalities. With respect to health outcomes in the first generation, our main results focus on survival beyond age 65. When studying survival, we left-censor the data such that all individuals in our analysis sample enter the risk period that we consider at age 50 (recall, our outcomes data start in 1980, which means that our oldest cohorts must have survived to age 50 to be observed in the data). In supplementary analyses, we have also examined several measures of hospital care utilization, as well as diagnoses for cardiovascular disease, heart disease, diabetes, and cancer. Lastly, we examine fertility decisions of first generation women born in 1935-1957 for whom we have complete fertility data. This analysis sheds light on an additional dimension of adult wellbeing and is instrumental for interpretation of the intergenerational results.

For the second generation, we study educational attainment by age 25 for children who are observed at this age in our data. The relatively young age of the second generation makes the analysis of health care utilization and survival underpowered, as hospital encounters, diagnoses, and deaths are rare. ${ }^{21}$ We observe completed years of schooling, an indicator for more than compulsory education, and an indicator for graduating gymnasium (an academic high school that students can attend following the nine years of compulsory education). Given that the average age at graduation from university is in the late 20s in Denmark, we lack power to examine this last margin of the educational distribution.

We start by graphically examining the impact of preschool exposure on our main outcomes in the first and second generation using event-study models. Figure 2 presents the event-study graphs for our main first and second generation outcomes; event-study graphs for additional first and second generation outcomes are presented in Appendix Figures A.3 and A.4. Importantly, the event-study models only use data from municipalities that implement the preschool program between 1934 and 1960, i.e., they exclude the "always-implementers". We estimate regressions that include indicators for the cohorts' ages in the year of preschool approval in their municipality of birth between -2 and 11, grouped into two-year bins to increase precision. ${ }^{22}$

Figures $2 \mathrm{a}$ and $2 \mathrm{~b}$ suggest that, relative to cohorts aged 6 to 7 at the time of preschool approval, those who were aged 3 years or less have a higher human capital index and an increased likelihood of survival past age 65. Cohorts aged 4 to 5 in the year of preschool approval do not appear to benefit significantly from access to preschool, although in principle

\footnotetext{
${ }^{21}$ We have analyzed second generation hospitalization, diagnoses, and survival outcomes, finding no statistically significant effects.

${ }^{22}$ Results from event-study models based on a more balanced sample of municipalities (with data for at least 8 years pre- and post- preschool approval) are very similar to the graphs presented here. In addition, event-study models using indicators for single ages of exposure are also similar but less precisely estimated.
} 
they were eligible to attend for a part of their preschool years. The coefficients on exposure at ages 8 to 9 and 10 to 11 are all statistically insignificant, suggesting that there are no pre-existing trends in the outcomes of cohorts who were too old to attend preschool when it first became approved in their municipality. In Figures $2 \mathrm{c}$ and $2 \mathrm{~d}$ we present the eventstudy estimates for years of schooling in the first and second generation, respectively. We do not detect any significant pre-trends in the educational attainment of either the first or second generation, and both graphs present suggestive evidence of an increase in education for exposed children and the children of exposed mothers (albeit not all coefficients are individually statistically significant).

Table 4 presents our main results for the long-term impacts of access to a governmentapproved preschool on the human capital index, its individual components, and survival past age 65 for the first generation. We show results from two specifications: Column (1) includes cohort and municipality fixed effects as well as controls for municipality time-varying characteristics, while in column (2) we also add a linear time trend interacted with county indicators.

Consistent with the graphical evidence, Table 4 shows that access to a high quality preschool improves children's long-term well-being. As we move from column (1) to column (2) the exact coefficient magnitudes change, but the effects remain positive and statistically significant. In our preferred specification in column (2), we find that, relative to the comparison cohorts, individuals who had an approved preschool in their municipality of birth by age 3 have a $0.024 \mathrm{SD}$ higher human capital index, and are 0.7 percentage points $(0.8$ percent at the control mean) more likely to survive beyond age 65. Table 4 also presents separate results for the three components of the human capital index, finding statistically significant impacts on all measures. Preschool-exposed cohorts have 0.1 more years of schooling (0.9 percent at the control mean), are 1.7 percentage points (3 percent) more likely to have completed more than compulsory education, and have 1.7 percent higher income than their counterparts without access to preschool at age $3 .^{23}$

As noted above, we have also examined additional health outcomes for the first genera-

\footnotetext{
${ }^{23}$ Appendix Table A.2 explores the effects of preschool on alternative measures of adult income: average age 30-60 wage income in levels, log of the present discounted value of age 30-60 wage income (following Chetty et al., 2011), log average age 30-60 total income, log average age 49-51 wage income (i.e., around age 50, when all of our cohorts are observed), and an indicator for any positive wage income at ages 49-51. We find positive coefficients on exposure to preschool for all of these outcomes, which are significant at least at the $10 \%$ level in 7 out of the 10 models. We have also explored differences in the effects on our main first generation outcomes by gender. The estimated coefficients for wage income are higher for men, while the estimated coefficients for survival beyond age 65 are higher for women. However, the gender differences are not statistically significant and we therefore do not focus on them here. Finally, in Appendix Table A.4, we show that our main estimates are identical when we use the underlying micro-data to estimate our regressions rather than the two-step approach described in Section 4.
} 
tion. In Appendix Table A.3, we show that preschool exposure has no significant impacts on the likelihood of receiving any of the diagnoses we consider. While our estimates suggest significant reductions in the number of nights spent at the hospital between ages 55 and 64, this finding appears to be sensitive to the exact age range considered. Consistent with earlier research, we find that NHV reduces the likelihood of being diagnosed with cardiovascular disease and heart disease (see Appendix Table B.4 and the discussion in Section 5.4 below.)

Having shown that preschool access has persistent positive effects on adult well-being throughout the life cycle, we next study whether these benefits transmit to the next generation. We first examine whether preschool exposure affects the fertility behavior of the (first generation) women in our analysis sample. We analyze the following outcomes: an indicator for remaining childless, total number of children, maternal age at first birth, and an indicator for the children's father's information being missing. Appendix Table A.5 shows - for the sample of women born in 1935-1957 for whom we have complete fertility data - that women with access to preschool are slightly older at their first birth (which is potentially driven by the increase in education that we find for the first generation). There are no significant impacts on the likelihood of remaining childless, the total number of children, or the likelihood of the father being missing from the children's birth certificates. These results suggest that any selection into fertility - and hence into our sample of second generation outcomes - is likely to be small. Table 5 presents results for the educational outcomes of the firstborn children of women born in 1935-1957. As with the analysis of first generation outcomes, we collapse our data into cells defined by the mothers' municipalities and years of birth (after estimating auxiliary regressions of the second generation outcomes on maternal month of birth indicators). We find that a mother's access to preschool at age 3 increases the likelihood that her child obtains more than a compulsory education by 0.9 percentage points $(1.2$ percent). While the estimates for the other second generation educational outcomes are also positive, they are not statistically significant in our preferred model in column (2). ${ }^{24}$

In sum, our results suggest that access to high quality public preschool for poor children has lasting impacts on the health and human capital of exposed cohorts, as well as the educational outcomes of their children.

\footnotetext{
${ }^{24}$ Results from analyses including all children (rather than just firstborns) of the first generation mothers are similar to those reported in Table 5 and presented in Appendix Table A.6. When we use the full sample of children — which, by construction, is on average younger than the sample of only the oldest children-we also find a significant effect of maternal preschool exposure on the likelihood that a child completes academic high school. We prefer our (more conservative) intergenerational estimates for firstborn children that circumvent any remaining concerns about endogenous fertility decisions with respect to number of children and birth spacing, and are based on a sample that has had time to progress further in their educational careers. We do not find heterogeneity of our second generation impacts by gender of the child in our firstborn sample.
} 


\subsection{Robustness}

To probe the sensitivity of our estimates, Appendix Tables A.7 and A.8 present results based on alternative specifications and sample restrictions, respectively. In columns (1) through (4) of Appendix Table A.7, we address concerns about the correlation between the timing of preschool approval and local area urbanicity through a variety of additional control variables. We: (1) include separate linear trends for urban and rural areas; (2) include an interaction between an indicator for cohorts born in 1946 or later and an indicator for a rural municipality to control for the impact of a 1958 schooling reform, which increased access to academic-track high schools for rural students (Arendt, 2008); (3) add rural municipality $\times$ decade fixed effects; and (4) replace the baseline indicator treatment variable with a variable for the fraction of years a cohort was exposed to an approved preschool between the ages of 3 and 6 . Out of the 12 reported coefficients for first and second generation main outcomes, 10 are statistically significant at the $5 \%$ level or lower. ${ }^{25}$

Columns (1) and (2) of Appendix Table A.8 restrict our sample to only the urban or rural municipalities, respectively. In column (3), we estimate our baseline equation (1) using only the sample of municipalities that approve a preschool during our sample period, i.e., the sample that is identical to the one used in event-study models discussed above. Finally, in column (4), we only include municipalities that ever implement an NHV program. In general, our results remain similar to those from the baseline model. We see significant effects in both the urban and rural samples for both of our main first generation outcomes. While the estimate for the effect of preschool approval on the human capital index is smaller and not significant at conventional levels ( $p$-value of 0.13 ) in the sample that excludes alwaysimplementers, in supplementary analyses we find significant and similarly sized effects for two of its three individual components (the two educational measures).

We have additionally checked whether our results are sensitive to defining treatment based on the year of first preschool establishment rather than the first government approval. In principle, municipalities where the first approval happened after the year of initial preschool establishment could be used to distinguish the effects of access to any preschool from a change in preschool quality resulting from government approval. In practice, however, only 62 municipalities have an approval year that is later than the initial establishment year, and we do not have enough power to detect separate impacts of the two treatments.

As another indirect test of the identifying assumption, we examine whether predicted

\footnotetext{
${ }^{25}$ The only exception is that when we consider an indicator for the second generation child having more than compulsory education in a model controlling for the impact of the schooling reform, the treatment coefficient becomes smaller in magnitude and no longer significant. However, based on the $95 \%$ confidence intervals, we cannot reject that the coefficient from this model is the same as those reported in columns (1) and (3).
} 
outcomes based on all available municipality characteristics are correlated with the timing of preschool approval. We regress each of our eight main outcomes in the first and second generation (which are already conditional on gender and month of birth fixed effects in the first generation) - the human capital index, its three individual components, survival beyond age 65, and the three educational attainment measures in the second generation - on all of the municipality characteristics, and then test whether the predicted variables are correlated with the timing of preschool approval, controlling for municipality and cohort fixed effects, as well as county linear trends. Appendix Tables A.9 and A.10 present the results, none of which is significant at the $5 \%$ level.

Finally, we ask the question: How likely is it that we would find an impact of preschool approval if, instead of using actual preschool approval years for our 138 municipalities, we used randomly assigned approval years? We perform permutation tests in which we randomly assign each of the municipalities a preschool approval year between 1921 and 1960, and then estimate model (1) using the placebo treatment indicator. Appendix Figure A.5 shows the cumulative density functions (CDFs) generated by 1,000 draws, with the locations of the true coefficients depicted using vertical lines. For all of our main outcomes in the first and second generation, the true coefficients fall above the $95^{\text {th }}$ percentile of the distribution, suggesting that our results would be very unlikely under random assignment of preschool approval years.

\subsection{Magnitudes and Discussion}

To assess the magnitudes of our estimates, we begin by comparing our first generation results to the existing literature on the effects of preschool on educational attainment. Havnes and Mogstad (2011) find that preschool access resulting from the 1970s universal preschool expansion in Norway led to a 0.06 year increase in average years of schooling. Our estimated 0.1 year increase in years of schooling is bigger, consistent with the Norwegian preschools' effects being largest for the least advantaged children (Havnes and Mogstad, 2011, 2015).

As in Havnes and Mogstad (2011), our estimates represent intent-to-treat (ITT) impacts, since we do not observe whether individuals in our outcome data actually attended preschool. However, given that we study a targeted rather than universal program, our treatment-onthe-treated (TOT) effects are substantially different.

To calculate approximate TOT effects for our setting, we must first estimate a preschool enrollment rate, which we can only do for the urban municipalities in our sample. We use data on the number of children enrolled in each preschool from the nine book publications, interpolate to get estimates of enrollment in every year, and then aggregate to the municipality $\times$ year level. Next, we use data on the number of survivors past age one in 
each urban municipality and calculate the share of children aged 3 to 6 who were enrolled in preschool in every year between 1939 and 1950. We begin in 1939 since that is the first year when we can observe all living 6-year-olds (our earliest data on births are from 1933). Moreover, we do not have municipality-level data on births past 1950. We then estimate "first stage" regressions on this limited sample, regressing the share of children enrolled on an indicator for at least one approved preschool in a municipality $\times$ year cell, controlling for municipality and year fixed effects. Appendix Table A.11 presents the results. When we consider all urban municipalities in column (1), we find that moving from zero to at least one approved preschool leads to about a 6 percentage point increase in the share of children enrolled in preschool. In column (2), we drop 9 municipalities that had at least one preschool established before 1939 that was not yet approved; the first stage estimate becomes a 10 percentage point increase in the share of children enrolled. This higher estimate is arguably more applicable to the other municipalities that are included in our main analysis (but excluded from these "first stage" regressions), which are more rural and less likely to have had a previously established preschool. In column (3), we focus on the "switcher" municipalities that move from zero to one approved preschool over the 1939-1950 time period - the first stage estimate here is an 8 percentage point increase, but is no longer statistically significant due to the substantially reduced sample size. Our results are in line with aggregate statistics published by Denmark's population commission in 1936 (The population commission, 1936), which reported that 1936 enrollment rates for Danish urban municipalities with preschools (excluding Copenhagen) ranged between 3 and 35 percent of all children in eligible cohorts (with an unweighted average of 10 percent).

The above analysis suggests that one can divide our estimates by around 0.1 to get approximate TOT effect sizes. Although the resulting TOT magnitudes may seem large when compared with the more recent Scandinavian studies on universal programs, it is likely that the disadvantaged children targeted by the preschools in our analysis may have had the most to gain from early education and improved nutrition and health care. In fact, our TOT effects are actually within the range of estimates produced by the literature on participation in targeted preschool programs in the U.S. For example, Garces et al. (2002) find that Head Start participation increases the likelihood of high school completion by 20 percentage points among whites. Our 1.7 percentage point increase in the likelihood of having more than compulsory education translates into an approximate TOT effect of 17 percentage points, which is quite comparable. Deming (2009) estimates that Head Start participants have $0.23 \mathrm{SD}$ higher summary index of young adult outcomes than their non-participant siblings; our 0.024 SD increase in the human capital index becomes a TOT effect of 0.24 $\mathrm{SD}$, which is remarkably similar. The effects of participation in small targeted preschool 
programs are even larger (especially for females): Heckman et al. (2010a)'s evaluation of the Perry Preschool program suggests that the highest grade completed is increased by almost 1 year, while the likelihood of high school graduation is nearly 50 percentage points higher for the treatment group than the control group; García et al. (2016)'s study of the Abecedarian program shows that average years of schooling increases by 1.8 to 2.1 years, while the high school graduation rate goes up by 13 to 25 percentage points. Our estimated TOT magnitudes of a 1 year increase in schooling and a 17 percentage point increase in more than compulsory education overlap with these estimates.

With regard to second generation outcomes, we can compare to the estimates from Barr and Gibbs (2017)'s study of the intergenerational effects of access to Head Start. They report a 13 percentage point increase in the likelihood of high school graduation and a 17 percentage point increase in the likelihood of having some college education within their "high-impact" estimation sample. Scaled by the approximate first stage estimate of 0.1 discussed above, our resulting TOT magnitude is a 10 percentage point increase in the likelihood of having more than a compulsory education, which is quite similar.

We can also use our estimates of the effects of preschool on educational attainment in the first and second generation to approximate an intergenerational transmission coefficient. Note that since not all first generation women have children, we have re-estimated our first generation models using only the mothers that we use to create our second generation sample. In our preferred specification, we find that access to preschool at age 3 increases years of schooling by 0.098 years and increases the probability of having completed more than compulsory schooling by 1.7 percentage points. Dividing the second generation coefficients by these yields transmission coefficients of $0.28\left(\frac{0.027}{0.098}\right)$ for years of schooling and $0.53\left(\frac{0.009}{0.017}\right)$ for the probability of having more than compulsory education. Interestingly, the transmission coefficient for years of schooling based on our quasi-experimental research design is similar to the existing estimate of the intergenerational correlation between parental and child schooling in Denmark for this time period, which is around 0.3 (Hertz et al., 2007).

Finally, while a lack of more comprehensive data precludes us from doing a formal costbenefit calculation, even under very conservative assumptions, the estimated benefits of Danish preschool for poor children likely outweigh the costs of the program. According to a historical report, the total cost of a preschool slot in 1949-50 - which includes spending by the national government, municipalities, philanthropic organizations, and parents - ranged between $\$ 1,661$ and $\$ 2,291$ (in 2012\$) for preschools outside and within Copenhagen, respectively (Børnesagens tidende, 1952). A preschool slot was more expensive in Copenhagen due to several factors such as longer opening hours and smaller size. Thus, the per-slot cost of attending preschool for the full four years ranged from $\$ 6,644$ to $\$ 9,164$, implying a total 
cost of preschool between $\$ 525,993,720$ and $\$ 725,497,660$ for the cohorts attending preschool around $1950 .{ }^{26}$ This cost is substantially lower when compared to other targeted programs such as the two-year U.S. Perry Preschool program, which has an estimated per-child cost of $\$ 20,225$ (in 2012\$) (Heckman et al., 2010b).

\subsection{Interaction Effects Between Preschool and NHV}

We next proceed to analyze whether access to the NHV program in infancy enhances or diminishes the positive long-term and intergenerational returns to preschool. As described in Section 4, these analyses leverage variation across municipalities and time in access to both preschool and NHV.

Table 6 presents results from estimating equation (2) for our two main outcomes of interest in the first generation. In these specifications, the main effects of preschool and NHV point to substantial improvements in the human capital index and the likelihood of survival for cohorts who were only exposed to either program (but not both). Note that the main effect estimates in Table 6 should not be directly compared to the main effects of either preschool or NHV in regressions without interactions (in Appendix Tables B.3 and B.4), as the main effects in Table 6 are conditional on the other program not being present.

Notably, the interaction coefficients in Table 6 are consistently opposite-signed. For cohorts who had NHV at birth, the positive impact of access to preschool at age 3 on the human capital index is reduced by a statistically significant 74 percent. The increase in the likelihood of survival past age 65 also appears to be lowered, although the interaction coefficient is not statistically significant. Further, the interaction coefficients for the second generation outcomes are also consistently opposite-signed from the main effects, albeit statistically insignificant (see Appendix Table A.13). While there is both geographical and time variation in the presence of the two programs that we study (recall Appendix Figures A.1 and A.2), it is possible that we are underpowered when studying interaction effects for the very long-term and intergenerational outcomes. ${ }^{27}$

One complication for the interpretation of the interaction results stems from the possible selective survival of weak infants due to NHV exposure. Wüst (2012) finds that NHV increases the likelihood of infant survival by $0.5-0.8$ percent. If the surviving infants have worse health and are less responsive to the benefits of preschool, then our negative interaction effect

\footnotetext{
${ }^{26}$ We calculate these numbers by multiplying the cost per child by the number of treated children in our time period. The number of treated children is our analysis sample $(879,647)$ multiplied by the approximate share of individuals aged 3-6 who attended preschool (0.09; see the dependent variable mean in Appendix Table A.11). Thus, we arrive at: $\$ 6,644^{*} 879,647^{*} 0.09=\$ 525,993,720$ and $\$ 9,164^{*} 879,647^{*} 0.09=\$ 725,497,660$.

${ }^{27}$ As mentioned in Section 3, we have worse data on the date of NHV implementation for the 28 municipalities that did not introduce NHV by 1949. In Appendix Table A.12, we show that our results are similar if we drop post-1949 cohorts born in these municipalities.
} 
may be in part driven by this change in the composition of the sample. To address this issue, before collapsing the data, we drop individuals born in NHV-treated municipalities who are in the $1^{\text {st }}$ percentile of the human capital index distribution, and estimate the interaction model on this constrained sample. Appendix Table A.14 presents the results, which are very similar to our main findings, implying that selective survival of NHV-exposed individuals is unlikely to explain our negative interaction effects. How do these estimates relate to existing models of human capital formation (Cunha and Heckman, 2007; Heckman and Masterov, 2007; Heckman and Mosso, 2014)? In order to interpret our results, it is important to acknowledge two facts: First, we do not have any data on parental private investments and therefore cannot study whether they serve as complements or substitutes in the human capital production function. Second, as with nearly all empirical research, our analysis is set in a specific institutional context. While other research studies policy interactions in educational investments at older ages (Johnson and Jackson, Forthcoming; Gilraine, 2017), our work sheds light on how health-related interventions during early childhood interact with one another.

In this context, we do not find evidence of dynamic complementarities; if anything, the negative interaction effects between preschool and NHV exposure suggest some substitutability between public investments during the early childhood period. Put differently, we find that high quality preschool can compensate for initial health disadvantages, as identified by a lack of exposure to the NHV program. While we do not have data to observe the underlying mechanisms directly, one hypothesis is that the two programs have overlapping health-related components. For instance, since NHV educated parents on hygiene, infant nutrition, and parent-child interactions, their children may have grown up in healthier home environments. NHV also facilitated contact between families and local health care providers, enabling children to obtain better preventative and acute health care. Consistent with the idea that NHV was primarily a shock to the health of exposed cohorts, we confirm earlier results of Hjort et al. (2017) in our sample of municipalities with an ever-approved preschool of long-term impacts of NHV on individuals' health outcomes measured at ages 55 to 65 (see Appendix Tables B.1 and B.2). As such, the public preschool program that we study, which offered similar health-related services but at slightly older ages (see Section 2), entailed a substantially less significant treatment for the NHV-exposed children than for their non-NHV counterparts. 


\section{Conclusion}

Although the existing literature has documented the importance of early childhood interventions, questions about whether their impacts persist over the life cycle and across generations remain open. Additionally, we know very little about the added value of a program in a population that is exposed to more than one intervention. In this paper, we make progress on these questions with (i) new quasi-experimental evidence on the very long-run and intergenerational effects of a high quality targeted preschool program, and (ii) an analysis of the interaction between exposure to preschool and an infant health intervention.

Using data on the timing of preschool approvals across Danish municipalities together with administrative data on outcomes for nearly one million Danish people born between 1930 and 1957, we document positive long-term effects of access to a high quality targeted preschool program. Cohorts with access to a government-approved preschool by age 3 have a 0.024 SD higher human capital index (driven by a 0.1 year increase in the average number of years of schooling, a 1.7 percentage point increase in the probability of completing more than compulsory education, and a 1.7 percent rise in average wage income over the ages of 30 to 60 ) and are 0.7 percentage points more likely to survive past age 65 . Moreover, we

show significant intergenerational impacts - children of women with preschool access are 0.9 percentage points (1.2 percent at the control group mean) more likely to have completed more than compulsory schooling by age 25 .

When we interact preschool access at age 3 with access to the NHV program in infancy, we find that the individuals only exposed to preschool benefit more from it than individuals who were also exposed to NHV. For people who had NHV at birth, the positive impact of preschool on the human capital index is reduced by 74 percent. The interaction coefficients for the likelihood of survival past age 65 as well as the second generation education outcomes are also negative, but not statistically significant at conventional levels. Our findings imply that two multifaceted early childhood public interventions may partially substitute for one another.

Since both programs were implemented at the municipality level, there may be concerns about "overlapping labor markets". In particular, one possibility is that NHV program implementation attracted nurses away from working at preschools, thereby leading to a reduction in preschool effectiveness. However, this is an unlikely explanation for our interaction results because home visiting nurses were highly specialized with additional training beyond standard nurse certification and not in the pool of typical preschool personnel.

Our results further suggest that, in a setting with limited public resources, it may be efficient to design programs that specifically target populations without prior exposure to 
other interventions. For instance, while many over-subscribed programs for low-income children allocate slots at random or on a "first-come, first-serve" basis, our evidence suggests that an allocation mechanism that considers (the lack of) participation in earlier programs as potentially leading to greater program benefits.

Lastly, our study suggests that a high quality preschool program with a health component can compensate for low initial health in a cost-effective way. Although low-income children face disadvantages at birth with regard to their health and parental resources, our results demonstrate that public preschools can offset some of these initial shortcomings and potentially reduce inequalities in outcomes over the life cycle and across generations.

\section{References}

Adhvaryu, A., Molina, T., Nyshadham, A. and Tamayo, J. (2015). Helping children catch up: Early life shocks and the Progresa experiment, University of Michigan, unpublished manuscript.

Aizer, A. and Cunha, F. (2012). The production of human capital in childhood: endowments, investments and fertility, Unpublished manuscript, Brown University.

Albouy, D. (2009). The unequal geographic burden of federal taxation. Journal of Political Economy, 117 (4), 635-667.

Almond, D. and Currie, J. (2011). Chapter 15: Human capital development before age five. In O. Ashenfelter and D. Card (eds.), Handbook of Labor Economics, Handbook of Labor Economics, vol. 4, Part 2, Elsevier, pp. 1315-1486.

-, - and Duque, V. (2017). Childhood Circumstances and Adult Outcomes: Act II. Working Paper 23017, National Bureau of Economic Research.

- and Mazumder, B. (2013). Fetal origins and parental responses. Annual Review of Economics, 5 (1), 37-56.

Anderson, M. L. (2008). Multiple inference and gender differences in the effects of early intervention: A reevaluation of the abecedarian, perry preschool, and early training projects. Journal of the American Statistical Association, 103 (484).

Angrist, J. and LAVY, V. (2009). The effects of high stakes high school achievement awards: Evidence from a randomized trial. American Economic Review, 99 (4), 13841414.

AREndT, J. (2008). In sickness and in health-till education do us part: Education effects on hospitalization. Economics of Education Review, 27 (2), 161-172.

Bailey, M., Sun, S. and Timpe, B. (2018). Prep school for poor kids: The long-run impacts of head start on human capital and economic self-sufficiency, University of Michigan, unpublished manuscript.

BARker, D. J. (1990). The fetal and infant origins of adult disease. BMJ: British Medical Journal, 301 (6761), 1111. 
BARR, A. and GiBBs, C. R. (2017). Breaking the cycle? intergenerational effects of an antipoverty program in early childhood, Texas A\&M University, unpublished manuscript.

BAuer, P. and Riphahn, R. T. (2004). Intergenerational transmission of educational attainment: Evidence from Switzerland on natives and second generation immigrants. Discussion paper, IZA.

Belfield, C. R., Nores, M., Barnett, S. and Schweinhart, L. (2006). The high/scope perry preschool program cost-benefit analysis using data from the age-40 followup. Journal of Human Resources, 41 (1), 162-190.

Bhalotra, S., Karlsson, M., Nilsson, T. et al. (2015). Infant health and longevity: evidence from a historical trial in Sweden. Discussion Paper 2015-08, IZA, Institute for Social and Economic Research.

Bitler, M. P., Hoynes, H. W. and Domina, T. (2014). Experimental evidence on distributional effects of Head Start. Working Paper 20434, National Bureau of Economic Research.

Black, S. E., Butikofer, A., Devereux, P. J. and Salvanes, K. G. (2013). This Is Only a Test? Long-Run Impacts of Prenatal Exposure to Radioactive Downfall. Working Paper 18987, National Bureau of Economic Research.

- and Devereux, P. J. (2011). Recent developments in intergenerational mobility. Handbook of Labor Economics, 4, 1487-1541.

—, - and Salvanes, K. G. (2009). Like father, like son? a note on the intergenerational transmission of iq scores. Economics Letters, 105 (1), 138-140.

BøRnESAGENS TIDENDE (1952). The economic situation of childcare-related institutions in 1949-50 [de forebyggende institutioners økonomi i 1949-50]. Børnesagens tidende, 47 (3), $31-34$.

Bütikofer, A., Løken, K. V. and Salvanes, K. (2014). Long-term consequences of access to well-child visits, Norwegian School of Economics, unpublished manuscript.

Buus, H. (2001). Sundhedsplejerskeinstitutionens Dannelse [The Introduction of the Danish Home Visiting Program]. Museum Tusculanum Press.

Campbell, F., Conti, G., Heckman, J. J., Moon, S. H., Pinto, R., Pungello, E. and PAN, Y. (2014). Early childhood investments substantially boost adult health. Science, 343 (6178), 1478-1485.

Carneiro, P. and Ginja, R. (2014). Long-term impacts of compensatory preschool on health and behavior: Evidence from head start. American Economic Journal: Economic Policy, 6 (4), 135-73.

CAscio, E. U. (2015). The promises and pitfalls of universal early education. IZA World of Labor.

Chetty, R., Friedman, J. N., Hilger, N., Saez, E., Schanzenbach, D. W. and YAGAN, D. (2011). How does your kindergarten classroom affect your earnings? evidence from project star. Quaterly Journal of Economics, 126 (4), 749-804.

-, Hendren, N., Kline, P., Saez, E. and Turner, N. (2014). Is the united states still a land of opportunity? recent trends in intergenerational mobility. The American Economic Review, 104 (5), 141-147. 
Cunha, F. and Heckman, J. (2007). The technology of skill formation. The American Economic Review, 97 (2), 31-47.

Currie, J., Davis, L. W., Greenstone, M. and Walker, R. (2015). Do housing prices reflect environmental health risks? evidence from more than 1600 toxic plant openings and closings. American Economic Review, 105 (2), 678-709.

- and Thomas, D. (1995). Does head start make a difference? American Economic Review, 85 (3), 341-364.

Danish Data Archive (). Statistical Danish Commune Archive. Archive data material.

Datta Gupta, N. and Simonsen, M. (2016). Academic performance and type of early childhood care. Economics of Education Review, 53, 217 - 229.

De HaAn, M. and Leuven, E. (forthcoming). Head start and the distribution of long term education and labor market outcomes. Journal of Labor Economics.

Deming, D. (2009). Early childhood intervention and life-cycle skill development: Evidence from head start. American Economic Journal: Applied Economics, pp. 111-134.

DICE Database (2015). Parental leave entitlements: historical perspective (around 18702014). Tech. rep., IFO Institute, Munich.

DNBH (1933-1950). Causes of Death in the Kingdom of Denmark. The Danish National Board of Health.

- (various years). Medical Report for the Kingdom of Denmark. The Danish National Board of Health.

Donald, S. and LANG, K. (2007). Inference with difference-in-differences and other panel data. Review of Economics and Statistics, 89 (2), 221-233.

East, C. N., Miller, S., Page, M. and Wherry, L. R. (2017). Multi-generational Impacts of Childhood Access to the Safety Net: Early Life Exposure to Medicaid and the Next Generation's Health. Working Paper 23810, National Bureau of Economic Research.

Garces, E., Thomas, D. and Currie, J. (2002). Longer-term effects of head start. The American Economic Review, 92 (4), 999-1012.

García, J. L., Heckman, J. J., Leaf, D. E. and Prados, M. J. (2016). The life-cycle benefits of an influential early childhood program. Working Paper 22993, National Bureau of Economic Research.

Garcia, J. L., Heckman, J. J. and Ziff, A. L. (2018). Gender differences in the benefits of an influential early childhood program. European economic review, 109, 9-22.

Gilraine, M. (2017). School accountability and the dynamics of human capital formation, University of Toronto, unpublished manuscript.

Greaves, E., Hussain, I., Rabe, B. and Rasul, I. (2019). Parental responses to information about school quality: Evidence from linked survey and administrative data, University of Bristol, unpublished manuscript.

Gunnsteinsson, S., Adhvaryu, A., Christian, P., Labrique, A., Sugimoto, J., Shamim, A. A. and West, K. P. J. (2014). Resilience to early-life shocks, University of Michigan, unpublished manuscript. 
Havnes, T. and Mogstad, M. (2011). No child left behind: Subsidized child care and children's long-run outcomes. American Economic Journal: Economic Policy, 3 (2), 97129.

- and - (2015). Is universal child care leveling the playing field? Journal of Public Economics, 127, 100-114.

Heckman, J. and Masterov, D. (2007). The productivity argument for investing in young children. Applied Economic Perspectives and Policy, 29.

-, Moon, S. H., Pinto, R., Savelyev, P. and Yavitz, A. (2010a). Analyzing social experiments as implemented: A reexamination of the evidence from the highscope perry preschool program. Quantitative economics, 1 (1), 1-46.

-, Pinto, R. and Savelyev, P. (2013). Understanding the mechanisms through which an influential early childhood program boosted adult outcomes. The American Economic Review, 103 (6), 1-35.

Heckman, J. J. and Karapakula, G. (2019a). Intergenerational and Intragenerational Externalities of the Perry Preschool Project. Working Paper 2019-033, Human Capital and Economic Opportunity Global Working Group.

- and - (2019b). The Perry Preschoolers at Late Midlife: A Study in Design-Specific Inference. Working Paper 2019-034, Human Capital and Economic Opportunity Global Working Group.

-, Moon, S. H., Pinto, R., Savelyev, P. A. and Yavitz, A. (2010b). The rate of return to the highscope perry preschool program. Journal of Public Economics, 94 (1), $114-128$.

- and Mosso, S. (2014). The economics of human development and social mobility. Annu. Rev. Econ., 6 (1), 689-733.

Herbst, C. M. (2017). Universal child care, maternal employment, and children's long-run outcomes: Evidence from the us lanham act of 1940. Journal of Labor Economics, 35 (2), $519-564$.

Hertz, T., Jayasundera, T., Piraino, P., Selcuk, S., Smith, N. and VerashchagINA, A. (2007). The inheritance of educational inequality: International comparisons and fifty-year trends. The BE Journal of Economic Analysis 8 Policy, 7 (2).

Hjort, J., Sø Lvsten, M. and Wüst, M. (2017). Universal investments in infant and longrun health - evidence from denmark's 1937 home visiting program. American Economic Journal: Applied Economics, 9 (4), 78-104.

Hoynes, H., Schanzenbach, D. W. and Almond, D. (2016). Long-run impacts of childhood access to the safety net. The American Economic Review, 106 (4), 903-934.

Isen, A., Rossin-Slater, M. and Walker, R. (2017). Every breath you take - every dollar you'll make: The long-term consequences of the clean air act of 1970. Journal of Political Economy, 125 (3).

Johnson, R. C. and JaCKsOn, C. K. (Forthcoming). Reducing inequality through dynamic complementarity: Evidence from head start and public school spending. American Economic Journal: Economic Policy. 
Kling, J. R., Liebman, J. B. and Katz, L. F. (2007). Experimental analysis of neighborhood effects. Econometrica, 75 (1), 83-119.

Kristensen, J. and BAyer, S. (2015). Kamp og status. De lange linjer $i$ børnehaveinstitutiones og padagogprofessionens historie 1820 til 2015 [The Danish history of preschools and the pedagogical profession 1820-2015].

LeE, C.-I. and Solon, G. (2009). Trends in intergenerational income mobility. The Review of Economics and Statistics, 91 (4), 766-772.

Ludwig, J. and Miller, D. (2007). Does head start improve children's life chances? evidence from a regression discontinuity design*. The Quarterly Journal of economics, 122 (1), 159-208.

Malamud, O., Pop-Eleches, C. and Urquiola, M. (2016). Interactions Between Family and School Environments: Evidence on Dynamic Complementarities? Working Paper 22112, National Bureau of Economic Research.

Masse, L. N. and Barnett, W. S. (2002). A benefit-cost analysis of the abecedarian early childhood intervention. Cost-Effectiveness and Educational Policy, Larchmont, NY: Eye on Education, Inc, pp. 157-173.

Notowidigdo, M. (2011). The incidence of local labor demand shocks. Tech. rep., National Bureau of Economic Research.

Olivetti, C. (2013). The female labor force and long-run development: the American experience in comparative perspective. Working Paper 19131, National Bureau of Economic Research.

Pedersen, C. B., Gotzsche, H., Mø ller, J. O. and Mortensen, P. B. (2006). The danish civil registration system. Danish Medical Bulletin, 53 (4), 441-450.

Pedersen, J. (2009). Danmarks økonomiske historie 1910-1960 [Denmark's economic history 1910-1960].

Pedersen, J. H., Petersen, K. and Christiansen, N. F. (eds.) (2011a). Dansk velfardshistorie Bind II (1898-1933) [The history of the Danish welfare state, Book II (18981933)].

—, - and — (eds.) (2011b). Dansk velfardshistorie Bind III (1933-1956) [The history of the Danish welfare state, Book III (1833-1956)].

Poulsen, H. (2002). Bescttelsesairene 1940-1945 [The years of occupation 1940-1945].

Schweinhart, L. J., Montie, J., Xiang, Z., Barnett, W. S., Belfield, C. R. and Nores, M. (2005). Lifetime effects: The High/Scope Perry Preschool study through age 40. Ypsilanti, MI: High/Scope Press.

Shapiro, J. (2006). Smart cities: Quality of life, productivity, and the growth effects of human capital. The Review of Economics and Statistics, 88 (2), 324-335.

SKJERNBæK, O. J. (various years). Institutioner til varn for børn og unge $i$ Danmark [Institutions for the protection of children and youth in Denmark].

Solon, G. (1992). Intergenerational income mobility in the united states. The American Economic Review, pp. 393-408. 
The Population COMMission (1936). Befolkningskommissionens bet ankninger Nr.1 [Conclusions of the population commission].

Thompson, O. (2017). Head start's long-run impact: Evidence from the program's introduction. Journal of Human Resources, pp. 0216-7735r1.

Vallgårda, S., Krasnik, A. and VrangBæK, K. (2001). Health care systems in transition: Denmark. Clinical Medicine, 3 (7), 464-469.

Wüst, M. (2012). Early interventions and infant health: Evidence from the danish home visiting program. Labour Economics, 19, 484-495.

-, Mortensen, E. L., Osler, M. and Sørensen, T. I. A. (2018). Universal infant health interventions and young adult outcomes. Health Economics, 27 (8), 1319-1324. 


\section{$7 \quad$ Figures and Tables}

Figure 1: Map of Danish Municipalities with an Approved Preschool by 1960 and Share of Municipalities with an Approved Preschool by Year

(a) Map of Denmark

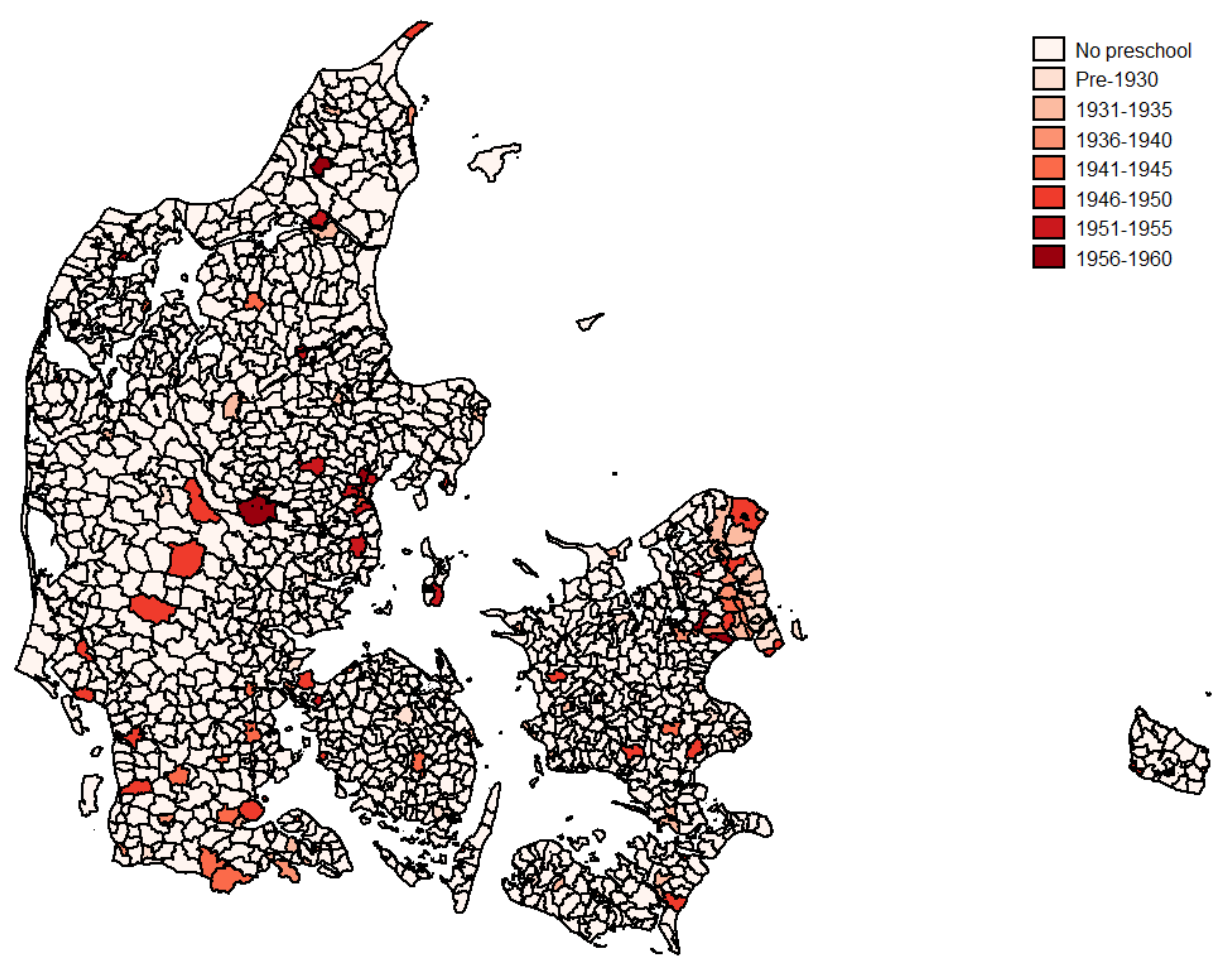

(b) Share with Approved Preschool by Year

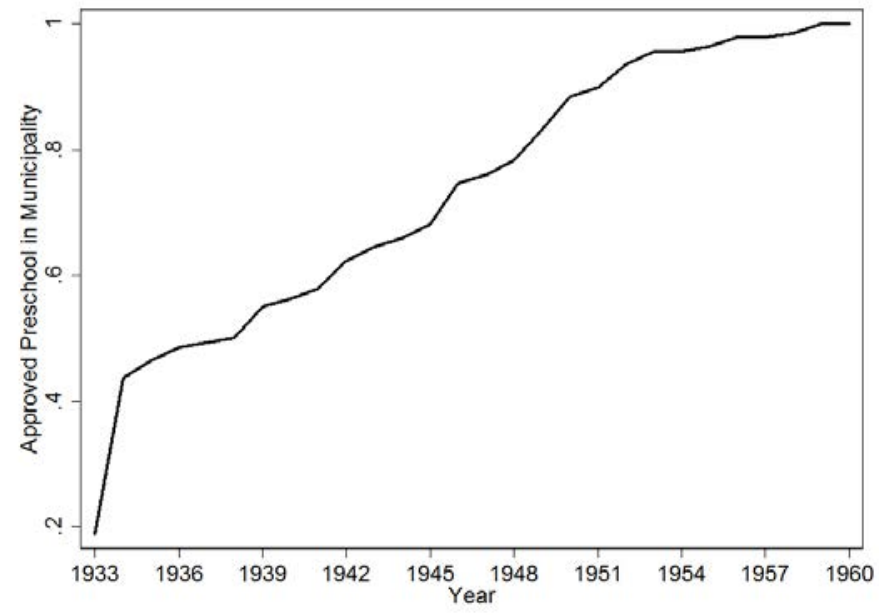

Notes: The map in sub-figure (a) shows the evolution of preschool approvals across Danish municipalities through 1960. Sub-figure (b) plots the share of municipalities that had an approved preschool in each year. Our analysis sample is limited to the 138 municipalities that ever had an approved preschool by 1960 . 
Figure 2: Effects of Access to Preschool by Age at Exposure: Human Capital Index, Survival Beyond Age 65 and Years of Schooling in the First and Second Generation

(a) Human Capital Index, First Gen

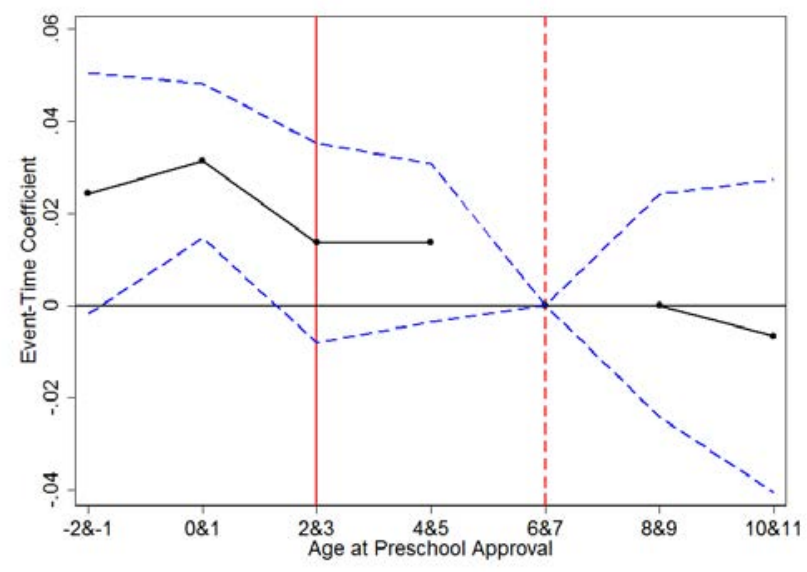

(c) Years of Schooling, First Gen

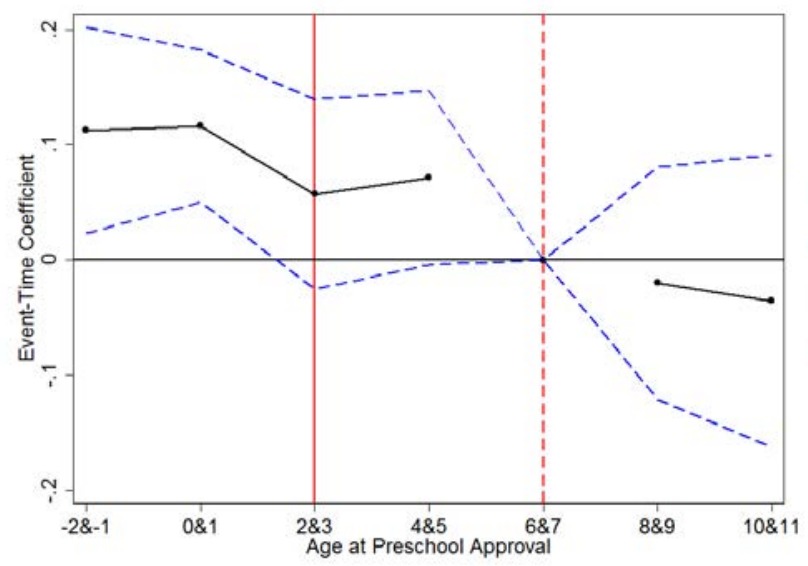

(b) Survival Beyond Age 65, First Gen

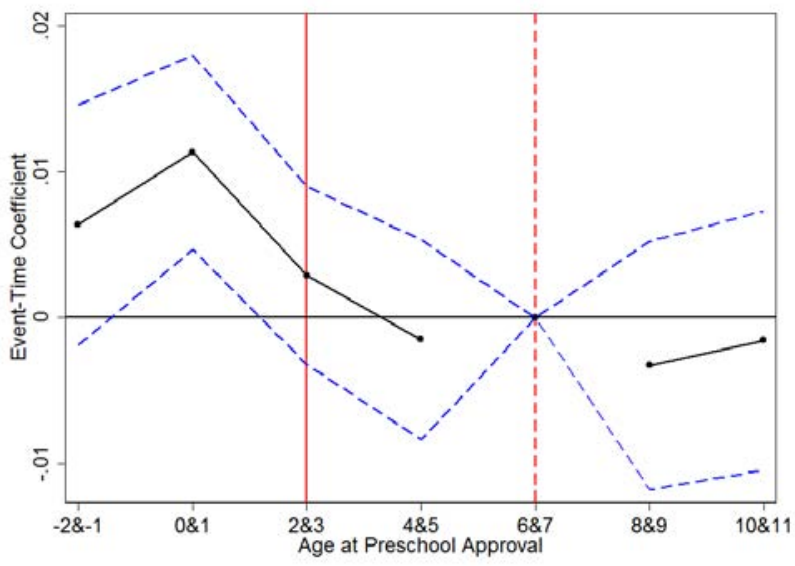

(d) Years of Schooling, Second Gen

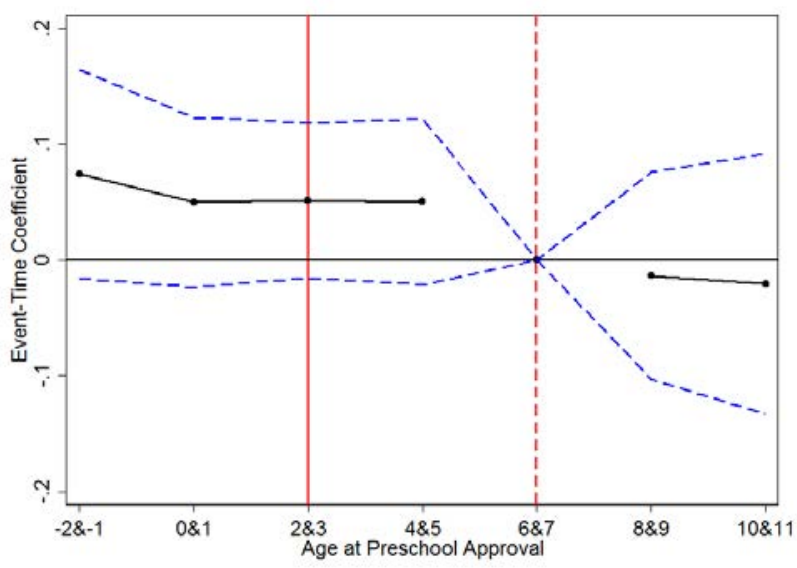

Notes: These figures show the coefficients and $95 \%$ confidence intervals from event-study regressions estimated on municipality $\times$ birth-year collapsed data. The human capital index is constructed using three measures: years of schooling, an indicator for having more than nine years of compulsory schooling, and the natural log of average wage income over all ages observable between 30 and 60 (see text for more details). For the first generation outcomes, before collapsing, we estimate an auxiliary regression on individual-level data, where we regress each outcome on gender and month-of-birth indicators, as well as municipality $\times$ birth-year fixed effects. We thus obtain conditional mean outcomes for each municipality $\times$ birth-year cohort, and use them as dependent variables. The first generation sample is limited to the 112 municipalities that approved a preschool between 1934 and 1960 (i.e., municipalities that already had an approved preschool by 1933 are dropped from event-study models). For the second generation outcome, we collapse the data to the level of the mother's municipality $\times$ birth-year. The second generation sample includes the 69 municipalities that introduced an approved preschool in the 1938-1960 period and excludes municipalities that had an approved preschool for this entire period (because we can only study children of mothers born in 1935 and later). All event-study regressions include indicators for the (first generation) cohorts' years of age in the year of the preschool approval in their municipality of birth between -2 and 11, grouped into two-year bins (with ages 6-7 as the omitted category). The regressions also include an indicator for cohorts being born more than two years after the preschool approval (i.e., age less than -2) and an indicator for cohorts being older than age 11 at the time of approval. The regressions include municipality and birth year fixed effects, county-specific linear time trends, as well as municipality time-varying controls (interpolated for years without data) for: $\log$ population, percent female, percent urban, percent ił 3 lustrial, percent agricultural, percent paying income tax, log taxable income, percent paying property tax, percent voting for the social democratic party, the radical liberal party, the agrarian liberal party, and the conservative party, respectively. The regressions are weighted by the number of observations in each municipality $\times$ birth-year cell. Standard errors are clustered 
Table 1: Municipality Characteristics in 1929-1930

(1)

(2)

(3)

All Munis Ever Approved Preschool No Approved Preschool

\begin{tabular}{lccc}
\hline Avg. Population & 2587.0 & 12927.8 & 1379.7 \\
Pct Social Demo & 25.5 & 46.6 & 23 \\
Pct Agrarian Lib & 47.4 & 21 & 50.5 \\
Pct Urban & 20 & 80.9 & 12.8 \\
Pct Agricultural & 57.1 & 17.7 & 61.8 \\
Pct Paying Income & 23.7 & 28.5 & 23.1 \\
Tax & 6.6 & 8.3 & 6.4 \\
Log Taxable Income & 5.8 & 5.3 & 5.9 \\
Pct Paying Property & & 138 & 1,182 \\
Tax & 1,320 & Num. Munis
\end{tabular}

Notes: Column (1) reports the means of municipality characteristics for all Danish municipalities with available data. Column (2) limits the sample to the 138 municipalities that ever had an approved preschool by 1960. Column (3) limits the sample to the municipalities that never had an approved preschool by 1960 .

Table 2: Correlation between Access to NHV at Birth and Access to Preschool at Age 3

(1)

NHV at Birth
(2)

Any Approved Preschool at Age 3

\begin{tabular}{lcc}
\hline Any Approved & 0.007 & \\
Preschool at Age 3 & {$[0.039]$} & 0.004 \\
NHV at Birth & & {$[0.025]$} \\
& & 0.914 \\
Mean, dept. var. & 0.738 & 3862 \\
\hline Observations (cells) & 3862 & .
\end{tabular}

Notes: Each column reports the results from a separate regression. The units of analysis are municipality $\times$ birth-year cells. The sample is limited to the 138 municipalities that ever had an approved preschool by 1960. All regressions include municipality and year-of-birth fixed effects, county-specific linear time trends, as well as municipality time-varying controls (interpolated for years without data) for: $\log$ population, percent female, percent urban, percent industrial, percent agricultural, percent paying income tax, log taxable income, percent paying property tax, percent voting for the social democratic party, the radical liberal party, the agrarian liberal party, and the conservative party, respectively. All regressions are weighted by the number of observations in each municipality $\times$ birth-year cell. Standard errors are clustered on the municipality level.

Significance levels: ${ }^{*} \mathrm{p}<0.1 * * \mathrm{p}<0.05^{* * *} \mathrm{p}<0.01$ 
Table 3: Do the 1920-1921 Municipality Characteristics Predict Preschool Approval Timing?

\begin{tabular}{|c|c|c|c|c|c|c|}
\hline & \multicolumn{3}{|c|}{ Urban Municipalities } & \multicolumn{3}{|c|}{ Rural Municipalities } \\
\hline & (1) & (2) & (3) & (4) & (5) & (6) \\
\hline & [Always] & [Early impl.] & [Impl. year] & [Always] & [Early impl.] & [Impl. year] \\
\hline \multirow[t]{2}{*}{ Ever NHV } & 0.145 & -0.093 & 2.628 & -0.055 & 0.045 & -1.639 \\
\hline & {$[0.278]$} & {$[0.288]$} & {$[4.730]$} & {$[0.102]$} & {$[0.170]$} & [2.326] \\
\hline \multirow[t]{2}{*}{ Pct Urban } & 0.003 & 0.015 & $-0.381^{*}$ & -0.002 & 0.004 & $-0.093^{* * *}$ \\
\hline & {$[0.012]$} & {$[0.012]$} & {$[0.209]$} & {$[0.002]$} & {$[0.003]$} & {$[0.034]$} \\
\hline \multirow[t]{2}{*}{ Log Population } & -0.533 & 0.342 & -14.762 & -0.205 & 0.065 & -4.845 \\
\hline & {$[0.587]$} & {$[0.608]$} & [11.841] & {$[0.214]$} & {$[0.357]$} & {$[5.468]$} \\
\hline \multirow[t]{2}{*}{ Pct Social Demo } & -0.003 & 0.004 & -0.040 & 0.002 & 0.002 & 0.178 \\
\hline & {$[0.007]$} & {$[0.007]$} & {$[0.132]$} & {$[0.004]$} & {$[0.007]$} & {$[0.120]$} \\
\hline \multirow[t]{2}{*}{ Pct Radical Lib } & 0.005 & 0.009 & -0.184 & 0.005 & -0.002 & 0.059 \\
\hline & {$[0.014]$} & {$[0.014]$} & {$[0.292]$} & {$[0.005]$} & {$[0.009]$} & {$[0.122]$} \\
\hline \multirow[t]{2}{*}{ Pct Agrarian Lib } & -0.002 & -0.011 & 0.137 & -0.001 & -0.002 & 0.001 \\
\hline & {$[0.008]$} & [0.008] & [0.149] & [0.004] & {$[0.006]$} & {$[0.090]$} \\
\hline \multirow[t]{2}{*}{ Pct Conservatives } & -0.008 & -0.001 & -0.071 & 0.004 & 0.003 & $-0.227^{*}$ \\
\hline & {$[0.010]$} & {$[0.010]$} & {$[0.173]$} & {$[0.006]$} & {$[0.010]$} & {$[0.135]$} \\
\hline Log Taxable & 0.674 & -0.303 & 13.561 & 0.262 & -0.044 & 3.253 \\
\hline Income & {$[0.553]$} & {$[0.573]$} & [11.517] & {$[0.184]$} & {$[0.306]$} & [4.799] \\
\hline Pct Paying & -0.004 & 0.030 & $-0.793^{*}$ & 0.007 & 0.013 & -0.205 \\
\hline Income Tax & {$[0.023]$} & {$[0.024]$} & {$[0.451]$} & {$[0.008]$} & {$[0.014]$} & {$[0.212]$} \\
\hline Pct Paying & -0.004 & -0.005 & -0.010 & -0.012 & 0.025 & -0.378 \\
\hline Property Tax & {$[0.017]$} & {$[0.018]$} & {$[0.319]$} & {$[0.011]$} & {$[0.019]$} & {$[0.277]$} \\
\hline Mean, dept. v: & 0.284 & 0.701 & 1940.08 & 0.099 & 0.408 & 1943.813 \\
\hline F-test & 1.900 & 1.613 & 1.523 & 2.050 & 1.920 & 2.963 \\
\hline $\mathrm{P}$-value joint $\mathrm{F}$-test & 0.064 & 0.127 & 0.170 & 0.043 & 0.060 & 0.005 \\
\hline Observations & 67 & 67 & 48 & 71 & 71 & 64 \\
\hline
\end{tabular}

Notes: Each column reports estimates from a separate regression. The units of analysis are the 138 municipalities that ever had an approved preschool by 1960 . We limit the sample to urban municipalities in the first three columns, and to rural municipalities in the last three columns. The dependent variables are: "Always" = an indicator for the municipality having an approved preschool prior to 1933; "Early" = an indicator for the municipality approving a preschool before 1940; "Approval Yr" = the approval year for municipalities that approve a preschool during the 1933-1960 analysis time period. The reported p-value is from an F-test of joint significance for all regressors. 
Table 4: Effects of Access to Preschool at Age 3 on Long-Term Human Capital Outcomes and Survival Past Age 65

\begin{tabular}{lcc}
\hline Outcome & $(1)$ & $(2)$ \\
\hline Human Capital Index & $0.046^{* * *}$ & $0.024^{* * *}$ \\
No. of obs. & {$[0.010]$} & {$[0.009]$} \\
\hline Yrs. of Schooling & 3862 & 3862 \\
Control Mean, dep. var. & $0.197^{* * *}$ & $0.099^{* * *}$ \\
No. of obs. & {$[0.045]$} & {$[0.038]$} \\
\hline More than Compulsory Educ. & 10.994 & 10.994 \\
Control Mean, dep. var. & 3862 & 3862 \\
No. of obs. & $0.031^{* * *}$ & $0.017^{* * *}$ \\
Log Avg Age 30-60 Wage Inc. & {$[0.006]$} & {$[0.005]$} \\
Control Mean, dep. var. & 0.569 & 0.569 \\
No. of obs. & 3862 & 3862 \\
\hline Survival beyond Age 65 & $0.028^{* * *}$ & $0.017^{*}$ \\
Control Mean, dep. var. & {$[0.010]$} & {$[0.009]$} \\
No. of obs. & 12.064 & 12.064 \\
\hline Cohort FE & 3862 & 3862 \\
Municipality FE & $0.005^{* *}$ & $0.007^{* * *}$ \\
County Controls & {$[0.002]$} & {$[0.002]$} \\
\hline
\end{tabular}

Notes: Each cell presents the coefficient for the treatment indicator from a separate regression. The human capital index is constructed using three measures: years of schooling, an indicator for having more than nine years of compulsory schooling, and the natural log of average wage income over all ages observable between 30 and 60 (see text for more details). The units of analysis are municipality $\times$ birth-year cells. Before collapsing, we estimate an auxiliary regression on the individual-level data, where we regress each outcome on gender and month-of-birth indicators, as well municipality $\times$ birth-year fixed effects. We thus obtain conditional mean outcomes for each municipality $\times$ birth-year cohort, and use them as dependent variables. The sample is limited to the 138 municipalities that ever had an approved preschool by 1960 . When studying survival beyond age 65 , the sample is limited to only those individuals who have survived to at least age 50. Municipality time-varying controls (interpolated for years without data) are: log population, percent female, percent urban, percent industrial, percent agricultural, percent paying income tax, log taxable income, percent paying property tax, percent voting for the social democratic party, the radical liberal party, the agrarian liberal party, and the conservative party, respectively. All regressions are 36 eighted by the number of observations in each municipality $\times$ birth-year cell. Standard errors are clustered on the municipality level.

Significance levels: ${ }^{*} \mathrm{p}<0.1 * * \mathrm{p}<0.05^{* * *} \mathrm{p}<0.01$ 
Table 5: Effects of Access to Preschool at Age 3 on the Education of the Next Generation

\begin{tabular}{lcc}
\hline Outcome & $(1)$ & $(2)$ \\
\hline Child's Years of Schooling & $0.042^{* *}$ & 0.027 \\
Control Mean, dep. var. & {$[0.020]$} & {$[0.020]$} \\
No. of obs. & 12.219 & 12.219 \\
Child Has More than Compulsory & 3151 & 3151 \\
Education & $0.013^{* * *}$ & $0.009^{* *}$ \\
Control Mean, dep. var. & {$[0.005]$} & {$[0.005]$} \\
No. of obs. & 0.747 & 0.747 \\
\hline Child Has Completed Gymnasium & 3151 & 3151 \\
Control Mean, dep. var. & $0.010^{*}$ & 0.007 \\
No. of obs. & $0.005]$ & {$[0.005]$} \\
\hline Cohort FE & 0.216 & 0.216 \\
Municipality FE & 3151 & 3151 \\
Muni Controls & Yes & Yes \\
County Trends & Yes & Yes \\
\hline
\end{tabular}

Notes: Each cell presents the coefficient for the treatment indicator from a separate regression. The units of analysis are cells based on the the mother's municipality $\times$ birth-year. Before collapsing, we estimate an auxiliary regression on the individual-level data, where we regress each outcome on monthof-birth indicators for the first generation, as well municipality $\times$ birth-year (of the first generation) fixed effects. We thus obtain conditional mean second generation outcomes for each maternal municipality $\times$ birth-year cohort, and use them as dependent variables. The sample is limited to the 138 municipalities that ever had an approved preschool by 1960. For information on control variables, see notes under Table 4 . All regressions are weighted by the number of observations in each municipality $\times$ birth-year cell. Standard errors are clustered on the municipality level.

Significance levels: ${ }^{*} \mathrm{p}<0.1{ }^{* *} \mathrm{p}<0.05^{* * *} \mathrm{p}<0.01$ 
Table 6: Interaction Effects between Access to NHV at Birth and Access to Preschool at Age 3 on Human Capital Index and Survival Past Age 65

(1)

Human Capital Index
(2)

Survival Past Age 65

\begin{tabular}{lcc}
\hline Any Approved & $0.028^{* * *}$ & $0.007^{* * *}$ \\
Preschool at Age 3 & {$[0.010]$} & {$[0.002]$} \\
NHV at Birth & $0.024^{* *}$ & $0.005^{*}$ \\
& {$[0.010]$} & {$[0.003]$} \\
Preschool x NHV & $-0.021^{* *}$ & -0.002 \\
& {$[0.010]$} & {$[0.003]$} \\
\hline Observations (cells) & 3862 & 3862
\end{tabular}

Notes: Each column reports the results from a separate regression. The human capital index is constructed using three measures: years of schooling, an indicator for having more than nine years of compulsory schooling, and the natural log of average wage income over all ages observable between 30 and 60 (see text for more details). The units of analysis are municipality $\times$ birth-year cells. Before collapsing, we estimate an auxiliary regression on the individual-level data, where we regress each outcome on gender and month-ofbirth indicators, as well municipality $\times$ birth-year fixed effects. We thus obtain conditional mean outcomes for each municipality $\times$ birth-year cohort, and use them as dependent variables. The sample is limited to the 138 municipalities that ever had an approved preschool by 1960 . When studying survival beyond age 65 , the sample is limited to only those individuals who have survived to at least age 50. All regressions include municipality and year-of-birth fixed effects, and county-specific linear trends, as well as municipality time-varying controls (interpolated for years without data). All regressions are weighted by the number of observations in each municipality $\times$ birth-year cell. Standard errors are clustered on the municipality level. Significance levels: * $\mathrm{p}<0.1 * * \mathrm{p}<0.05 * * * \mathrm{p}<0.01$ 


\section{A Additional Results}

Appendix Figure A.1: Variation in Preschool and NHV Availability by Year of Birth

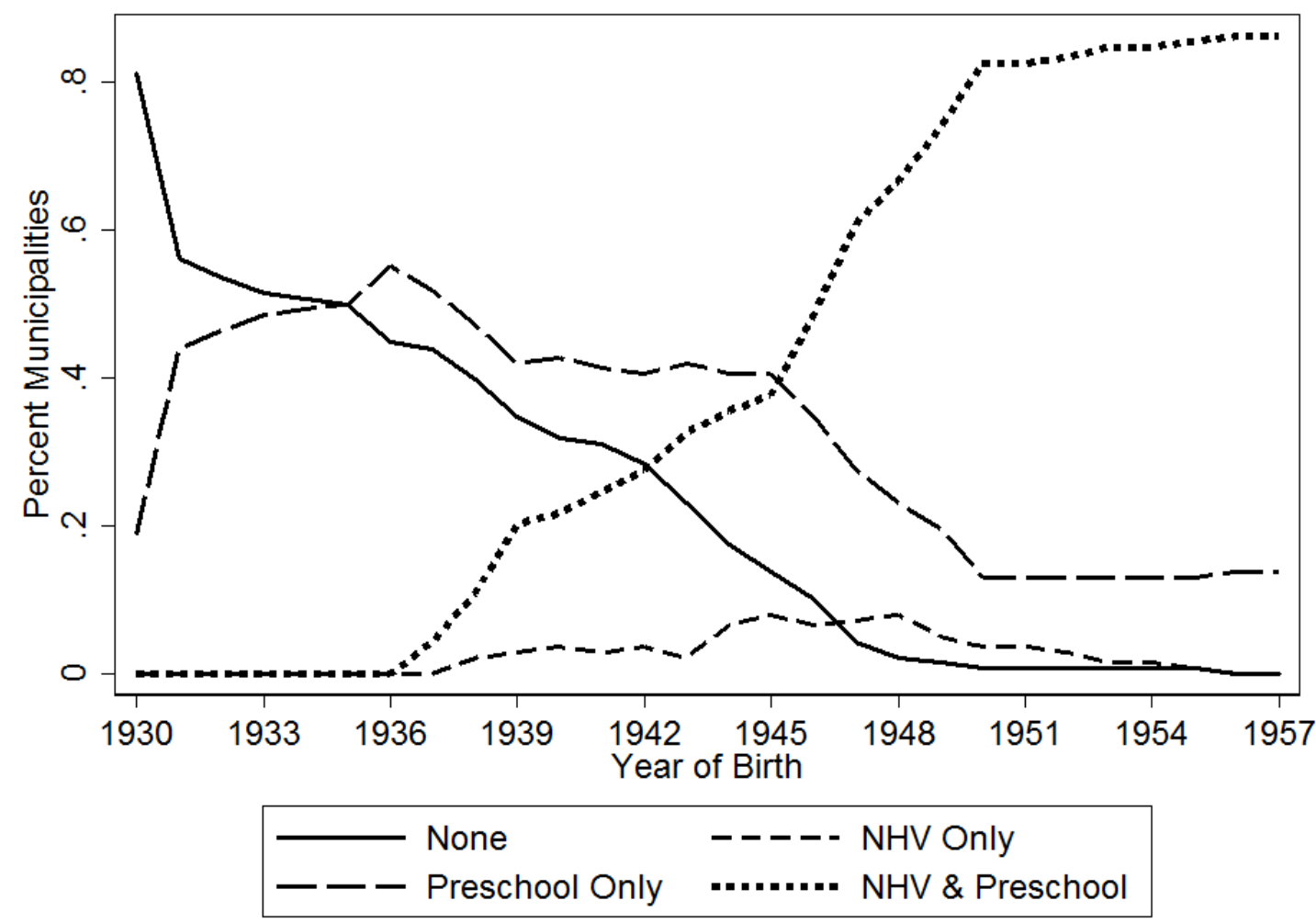

Notes: This graph shows for each cohort the percentage of municipalities that had: (1) no preschool at age 3 and no NHV at birth in solid black line; (2) preschool at age 3 but no NHV at birth in long dashed line; (3) NHV at birth but no preschool at age 3 in short dashed line; and (4) preschool at age 3 and NHV at birth in dotted line. The sample is limited to the 138 municipalities that ever had an approved preschool by 1960. 
Appendix Figure A.2: Difference in Years Between Preschool and NHV Availability

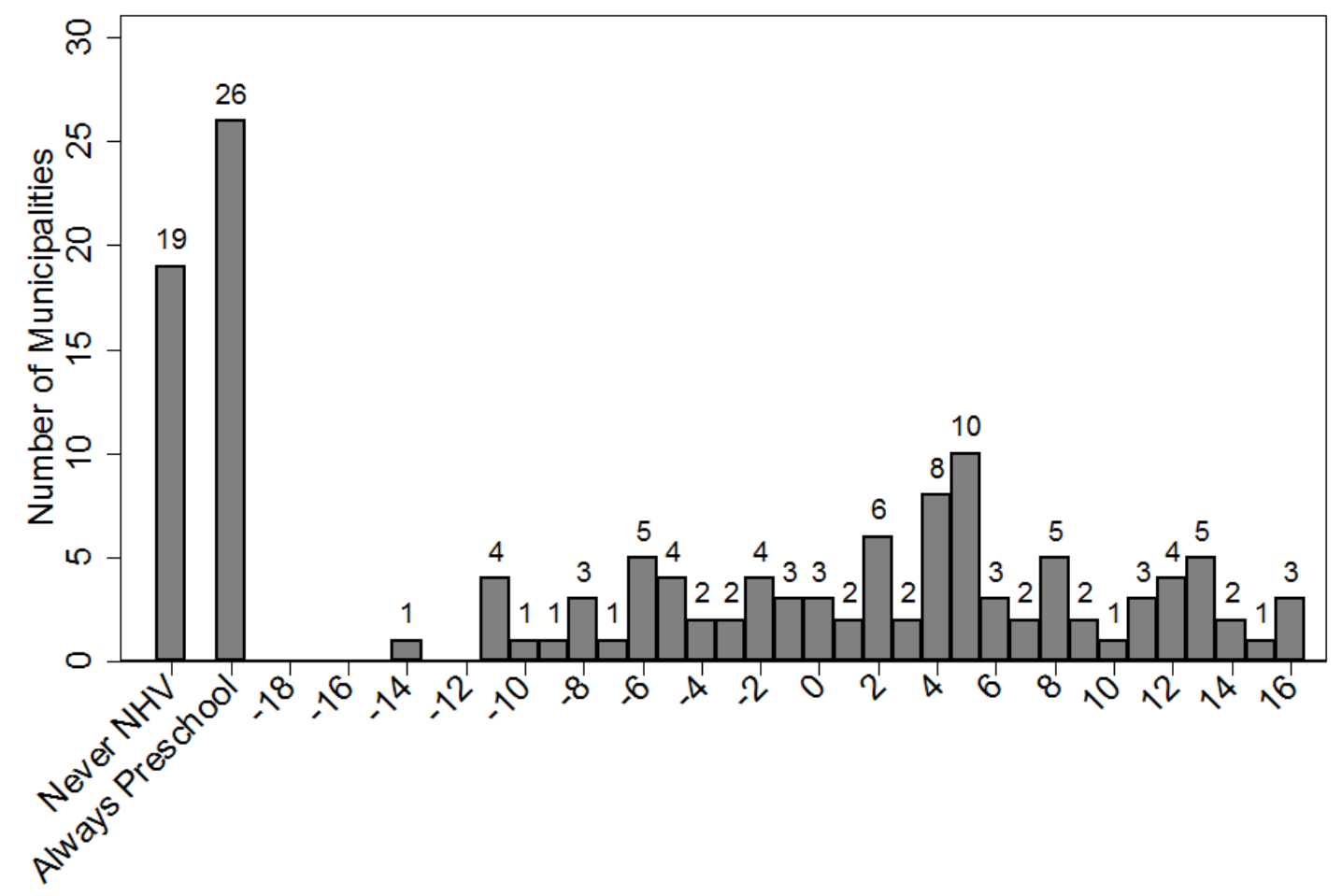

Distance Preschool Approval and NHV Introduction (Years)

Notes: This figure shows a histogram of the difference in years between the year in which a cohort had a first approved preschool at age 3 and the year in which a cohort had the NHV program at birth, for municipalities that approved a preschool from 1933 onward. So, if $y_{p}=$ year of preschool approval, and $y_{n}=$ year of NHV implementation, then we are showing the distribution of $d=y_{p}-3-y_{n}$. The sample is limited to the 138 municipalities that ever had an approved preschool by 1960. In this sample, 19 municipalities never established NHV ("Never NHV"), and 26 municipalities had an approved preschool by 1933 ("Always Preschool"). 
Appendix Figure A.3: Effects of Access to Preschool by Age at Exposure: Compulsory Schooling and Wage Income (Components of the Human Capital Index)

(a) More than Compulsory Schooling

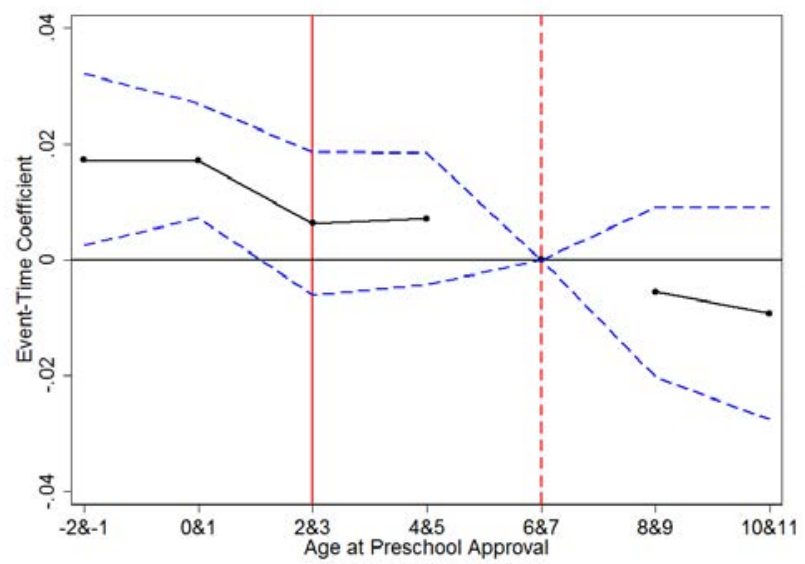

(b) Log Mean Wage Income between Ages 30 and 60

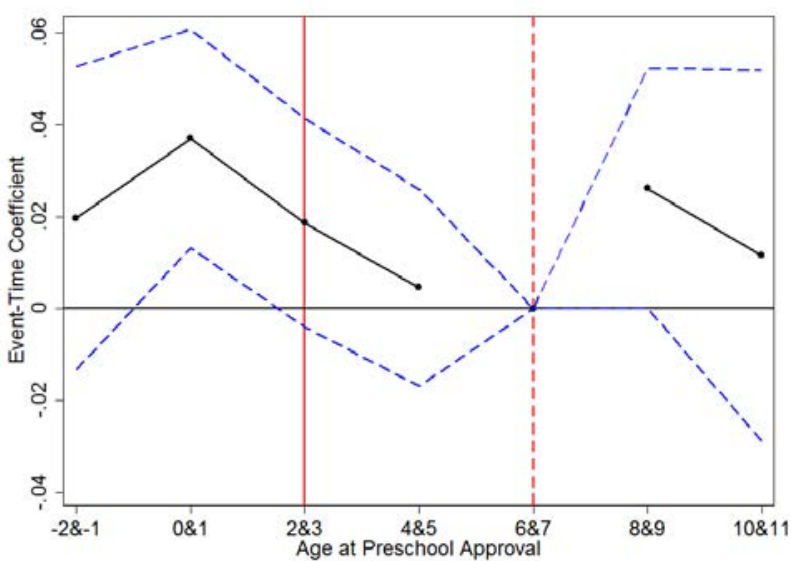

Notes: These figures show the coefficients and $95 \%$ confidence intervals from event-study regressions estimated on the municipality $\times$ birth-year collapsed data. See notes under Figure 2 for more details on the sample and specifications.

Appendix Figure A.4: Effect of Access to Preschool by Age at Exposure: Additional Educational Outcomes for the Next Generation

(a) More than Compulsory Schooling

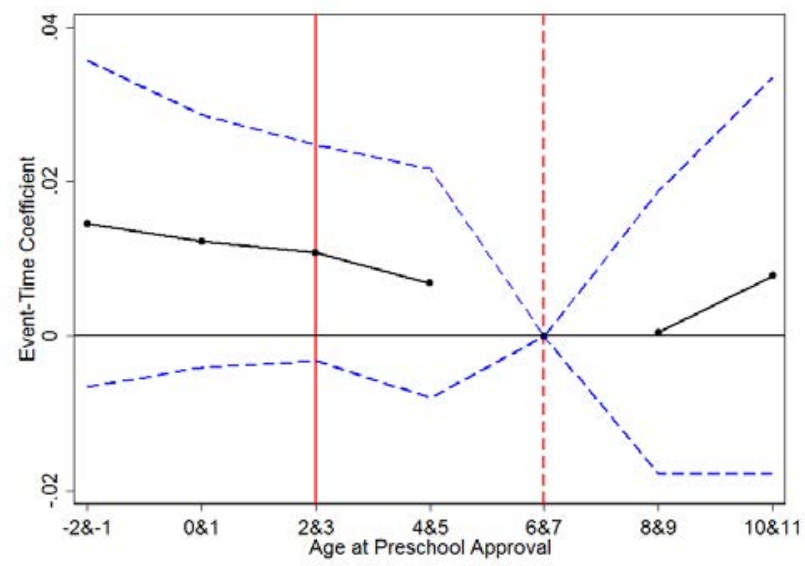

(b) Gymnasium

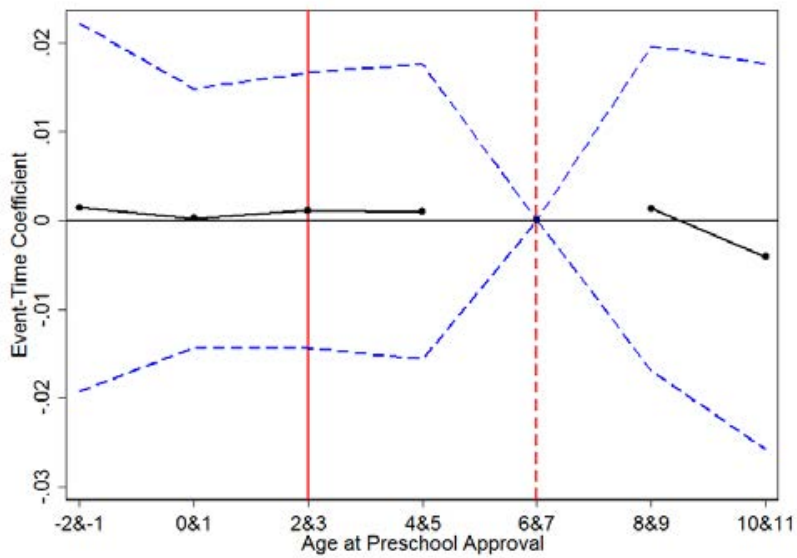

Notes: These figures show the coefficients and $95 \%$ confidence intervals from event-study regressions estimated on the municipality $\times$ birth-year collapsed data. See notes under Figure 2 for more details on the sample and specifications. 


\section{Appendix Figure A.5: Permutation Tests for Main Outcomes: CDFs of Coefficient Estimates}

from 1,000 Random Draws of Placebo Treatment Years

(a) Human Capital Index, First Gen.

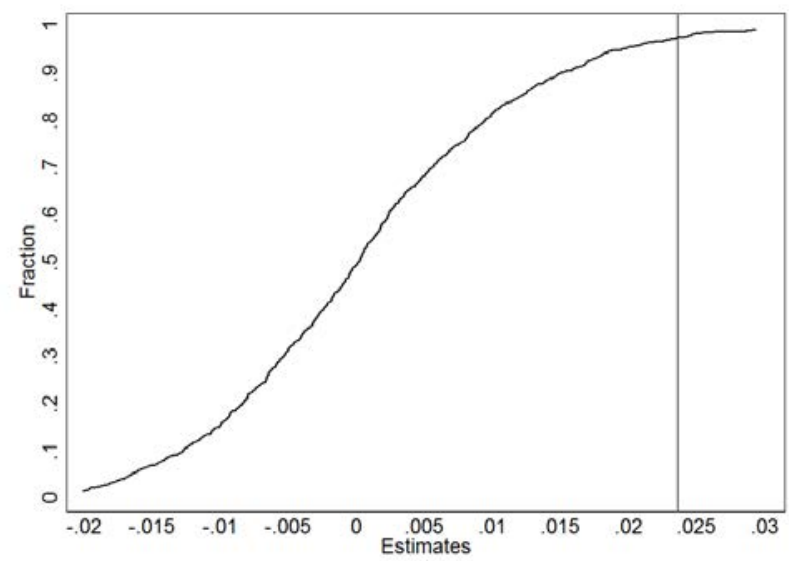

(c) More than Compulsory Schooling, Second Gen.

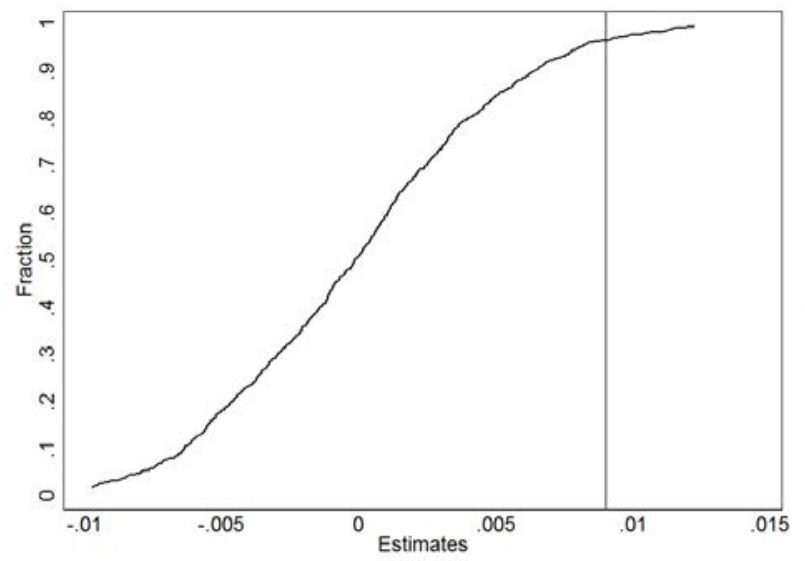

(b) Survival Beyond Age 65, First Gen.

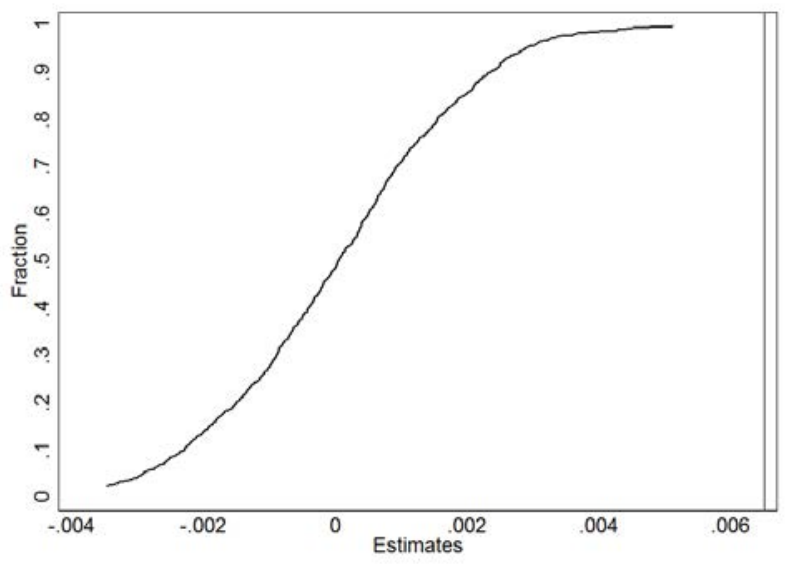

(d) Gymnasium, Second Gen.

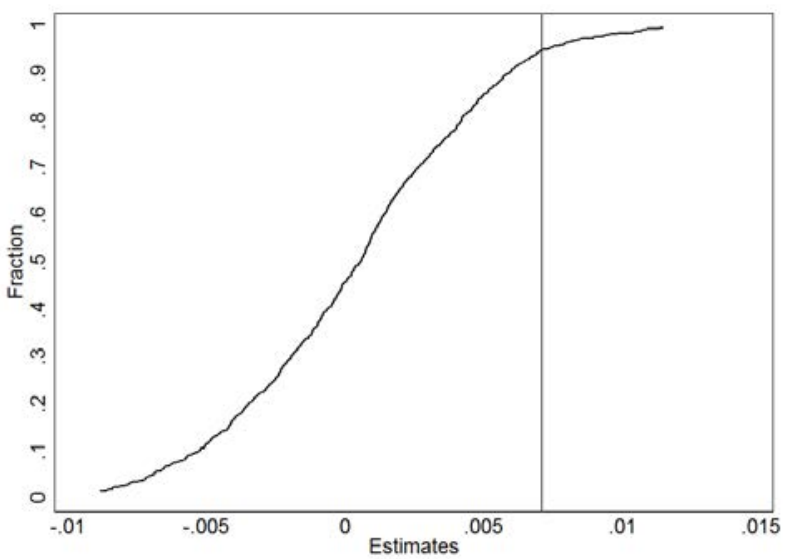

Notes: These figures show the cumulative density functions (cdfs) from a permutation test in which, in each of 1,000 iterations, each of the 138 municipalities in our sample is randomly assigned a preschool approval year between 1921 and 1960 instead of the true approval year. The vertical lines show the locations of the true coefficients from our preferred specification for each of our main outcomes. For further details on sample and specifications see notes under Tables 4 and 5 . 
Appendix Table A.1: Effects of Approved Preschool Availability on the Number of Births in the Subsequent Three Years; Urban Municipalities

\begin{tabular}{|c|c|c|c|}
\hline & \multicolumn{3}{|c|}{ Number of Births in Next 3 Years } \\
\hline & $\begin{array}{c}(1) \\
\text { [Ever Preschool] }\end{array}$ & $\begin{array}{c}(2) \\
{[\text { No Non-App. Preschool] }}\end{array}$ & $\begin{array}{c}(3) \\
\text { [1933-1947 Switchers] }\end{array}$ \\
\hline $\begin{array}{l}\text { Any Approved } \\
\text { Preschool }\end{array}$ & $\begin{array}{l}-182.4 \\
{[147.6]}\end{array}$ & $\begin{array}{l}-394.5 \\
{[234.3]}\end{array}$ & $\begin{array}{c}33.68 \\
{[42.66]}\end{array}$ \\
\hline $\begin{array}{l}\text { Mean, dep. var. } \\
\text { Observations }\end{array}$ & $\begin{array}{l}1620.3 \\
1020\end{array}$ & $\begin{array}{c}2379.7 \\
525\end{array}$ & $\begin{array}{c}675.5 \\
735\end{array}$ \\
\hline
\end{tabular}

Notes: Each cell presents the coefficient for an indicator for there being an approved preschool in a given municipality $\times$ year based on separate regressions. The data on births are for urban municipalities in the years 19331950. In column (1) the sample is limited to urban municipalities that ever had an approved preschool by 1960. Column (2) further drops municipalities that had at least one established but not approved preschool over this time period. Column (3) only uses municipalities that approved a preschool between 1933 and 1947.

Significance levels: $* \mathrm{p}<0.1 * * \mathrm{p}<0.05 * * * \mathrm{p}<0.01$ 
Appendix Table A.2: Effects of Access to Preschool at Age 3 on Different Adult Income Measures

\begin{tabular}{lcc}
\hline Outcome & $(1)$ & $(2)$ \\
\hline Avg Age 30-60 Wage Inc & $4326.430^{* *}$ & 1790.183 \\
& {$[1823.029]$} & {$[1552.952]$} \\
Control Mean, dep. var. & $2.36 \mathrm{e}+05$ & $2.36 \mathrm{e}+05$ \\
No. of obs. & 3862 & 3862 \\
\hline Log Age 30-60 PDV Wage & $0.027^{* * *}$ & $0.016^{*}$ \\
Inc & {$[0.010]$} & {$[0.009]$} \\
Control Mean, dep. var. & 14.265 & 14.265 \\
No. of obs. & 3862 & 3862 \\
\hline & $0.017^{* *}$ & 0.009 \\
Log Avg Age 30-60 Tot Inc & {$[0.007]$} & {$[0.006]$} \\
& 12.326 & 12.326 \\
Control Mean, dep. var. & 3862 & 3862 \\
No. of obs. & $0.014^{*}$ & 0.010 \\
\hline Log Avg Age 49-51 Wage & {$[0.008]$} & {$[0.009]$} \\
Inc & 12.276 & 12.276 \\
Control Mean, dep. var. & 3723 & 3723 \\
No. of obs. & $0.005^{*}$ & $0.004^{*}$ \\
\hline Any Wage Inc., Age 49-51 & {$[0.002]$} & {$[0.002]$} \\
& 0.892 & 0.892 \\
Control Mean, dep. var. & 3723 & 3723 \\
No. of obs. & Yes & Yes \\
\hline Cohort FE & Yes & Yes \\
Municipality FE & Yes & Yes \\
Muni Controls & No & Yes \\
County Trends & & \\
\hline
\end{tabular}

Notes: Each cell presents the coefficient for the treatment indicator from a separate regression. The units of analysis are municipality $\times$ birth-year cells. The outcomes are: average age 30 60 wage income in levels, log of the present discounted value of age 30-60 wage income (following Chetty et al., 2011), log average age 30-60 total income, log average age 49-51 wage income, and an indicator for any positive wage income at ages 49-51. See notes under Table 4 for more details on specifications and controls.

Significance levels: ${ }^{*} \mathrm{p}<0.1 * * \mathrm{p}<0.05 * * * \mathrm{p}<0.01$ 
Appendix Table A.3: Effects of Access to Preschool at Age 3 on Adult Health Care Utilization and Diagnoses

\begin{tabular}{|c|c|c|}
\hline Outcome & (1) & (2) \\
\hline Hosp. Nights: Age 45-54 & $\begin{array}{c}0.103 \\
{[0.152]}\end{array}$ & $\begin{array}{c}0.119 \\
{[0.154]}\end{array}$ \\
\hline $\begin{array}{l}\text { Control Mean, dep. var. } \\
\text { No. of obs. }\end{array}$ & $\begin{array}{l}8.666 \\
3862\end{array}$ & $\begin{array}{l}8.666 \\
3862\end{array}$ \\
\hline Hosp. Nights: Age 55-64 & $\begin{array}{c}-0.382^{* *} \\
{[0.192]}\end{array}$ & $\begin{array}{l}-0.390^{*} \\
{[0.200]}\end{array}$ \\
\hline Control Mean, dep. var. & 12.415 & 12.415 \\
\hline No. of obs. & 3862 & 3862 \\
\hline Hosp. Nights: Age 65-74 & $\begin{array}{c}0.197 \\
{[0.140]}\end{array}$ & $\begin{array}{c}0.200 \\
{[0.153]}\end{array}$ \\
\hline Control Mean, dep. var. & 12.881 & 12.881 \\
\hline No. of obs. & 3862 & 3862 \\
\hline Diagnosed Cardio & $\begin{array}{c}0.002 \\
{[0.003]}\end{array}$ & $\begin{array}{c}0.001 \\
{[0.003]}\end{array}$ \\
\hline Control Mean, dep. var. & 0.220 & 0.220 \\
\hline No. of obs. & 3862 & 3862 \\
\hline Diagnosed Heart & $\begin{array}{l}-0.001 \\
{[0.002]}\end{array}$ & $\begin{array}{l}-0.001 \\
{[0.002]}\end{array}$ \\
\hline Control Mean, dep. var. & 0.074 & 0.074 \\
\hline No. of obs. & 3862 & 3862 \\
\hline Diagnosed Diabetes & $\begin{array}{l}-0.001 \\
{[0.001]}\end{array}$ & $\begin{array}{l}-0.001 \\
{[0.001]}\end{array}$ \\
\hline Control Mean, dep. var. & 0.031 & 0.031 \\
\hline No. of obs. & 3862 & 3862 \\
\hline Diagnosed Cancer & $\begin{array}{l}-0.001 \\
{[0.001]}\end{array}$ & $\begin{array}{l}-0.000 \\
{[0.001]}\end{array}$ \\
\hline Control Mean, dep. var. & 0.043 & 0.043 \\
\hline No. of obs. & 3862 & 3862 \\
\hline Cohort FE & Yes & Yes \\
\hline Municipality FE & Yes & Yes \\
\hline Muni Controls & Yes & Yes \\
\hline County Trends & No & Yes \\
\hline
\end{tabular}

Notes: Each cell presents the coefficient for the treatment indicator from a separate regression. The units of analysis are municipality $\times$ birth-year cells. The outcomes are: the number of nights spent at the hospital over different age ranges, as well as diagnoses for cardiovascular disease, heart disease, diabetes, and cancer. See notes under Table 4 for more details on specifications and controls.

Significance levels: ${ }^{*} \mathrm{p}<0.1 * * \mathrm{p}<0.05^{* * *} \mathrm{p}<0.01$ 
Appendix Table A.4: Effects of Access to Preschool at Age 3 on Main Outcomes; Individuallevel Micro-Data

\begin{tabular}{lcccccc}
\hline & \multicolumn{2}{c}{ First Generation Outcomes } & & \multicolumn{2}{c}{ Second Generation Outcomes } \\
\cline { 2 - 3 } & $(1)$ & $(2)$ & & $(3)$ & $(4)$ & $(5)$ \\
& HC Index & Survival>Age 65 & & Yrs.School & $\geq$ Comp. Edu. & Gym. \\
\hline Any Approved & $0.024^{* * *}$ & $0.007^{* * *}$ & & 0.029 & $0.009^{* *}$ & 0.007 \\
Preschool at Age 3 & {$[0.008]$} & {$[0.002]$} & & {$[0.019]$} & {$[0.004]$} & {$[0.005]$} \\
\hline Observations & 796648 & 880708 & & 316530 & 316530 & 316530 \\
\hline
\end{tabular}

Notes: Each coefficient is from a separate regression that uses individual-level data. Standard errors are clustered on the municipality level. The human capital index is constructed using three measures: years of schooling, an indicator for having more than nine years of compulsory schooling, and the natural log of average wage income over all ages observable between 30 and 60 (see text for more details). All regressions control for municipality and birth year fixed effects (of the first generation), municipality time-varying controls, and county-specific linear trends. Standard errors are clustered at the municipality level.

Significance levels: $* \mathrm{p}<0.1 * * \mathrm{p}<0.05^{* * *} \mathrm{p}<0.01$

Appendix Table A.5: Effects of Access to Preschool at Age 3 on the Fertility Outcomes of Females Born in 1935-1957

(1)

$(2)$

(3)

(4)

No Kids Num. Kids Age at Fst. Birth Dad Ever Miss.

\begin{tabular}{lcccc}
\hline Any Approved & -0.004 & 0.003 & $0.116^{* *}$ & -0.002 \\
Preschool at Age 3 & {$[0.004]$} & {$[0.015]$} & {$[0.051]$} & {$[0.004]$} \\
\hline Control Mean, dep. var. & 0.096 & 2.130 & 23.711 & 0.140 \\
Observations (cells) & 3161 & 3161 & 3156 & 3161 \\
\hline
\end{tabular}

Notes: Each column reports the results from a separate regression. The units of analysis are municipality $\times$ birth-year cells. The sample is limited to females who were born in 1935-1957 in the 138 municipalities that ever had an approved preschool by 1960. See notes under Table 4 for more details on specifications and controls.

Significance levels: ${ }^{*} \mathrm{p}<0.1 * * \mathrm{p}<0.05 * * * \mathrm{p}<0.01$ 
Appendix Table A.6: Effects of Access to Preschool at Age 3 on the Education of the Next Generation, Using All (Rather than Firstborn) Children

\begin{tabular}{lcc}
\hline Outcome & $(1)$ & $(2)$ \\
\hline Child's Years of Schooling & $0.041^{* *}$ & 0.032 \\
& {$[0.019]$} & {$[0.022]$} \\
Control Mean, dep. var. & 12.131 & 12.131 \\
No. of obs. & 3153 & 3153 \\
\hline Child Has More than & $0.013^{* * *}$ & $0.010^{*}$ \\
Compulsory Education & {$[0.005]$} & {$[0.005]$} \\
Control Mean, dep. var. & 0.730 & 0.730 \\
No. of obs. & 3153 & 3153 \\
\hline Child Has Completed & $0.012^{* * *}$ & $0.011^{* *}$ \\
Gymnasium & {$[0.004]$} & {$[0.004]$} \\
Control Mean, dep. var. & 0.202 & 0.202 \\
No. of obs. & 3153 & 3153 \\
\hline Cohort FE & Yes & Yes \\
Municipality FE & Yes & Yes \\
Muni Controls & Yes & Yes \\
County Trends & No & Yes \\
\hline
\end{tabular}

Notes: Each cell presents the coefficient for the treatment indicator for a separate regression. The units of analysis are cells based on the mother's municipality $\times$ birth-year. The analyses are identical to those in Table 5, except we use a sample of all children of mothers born in 1935-1957 rather than only the firstborns. See notes under Table 5 for more details on specifications and controls.

Significance levels: ${ }^{*} \mathrm{p}<0.1{ }^{* *} \mathrm{p}<0.05^{* * *} \mathrm{p}<0.01$ 
Appendix Table A.7: Robustness to Changes in Specification

\begin{tabular}{lcccc}
\hline Outcome & $(1)$ & $(2)$ & $(3)$ & $(4)$ \\
& $($ Rural Trends) & $($ Edu. Ref.) & $($ Rural*Decade) & $($ Frac Yrs) \\
\hline Human Capital Index & $0.028^{* * *}$ & $0.017^{*}$ & $0.047^{* * *}$ & $0.041^{* * *}$ \\
& {$[0.009]$} & {$[0.009]$} & {$[0.015]$} & {$[0.012]$} \\
No. of obs. & 3862 & 3862 & 3862 & 3862 \\
\hline Survival Past Age 65 & $0.006^{* * *}$ & $0.005^{* *}$ & $0.006^{* * *}$ & $0.007^{* * *}$ \\
& {$[0.002]$} & {$[0.002]$} & {$[0.002]$} & {$[0.003]$} \\
No. of obs. & 3862 & 3862 & 3862 & 3862 \\
\hline Second Gen.: More than & $0.015^{* * *}$ & 0.007 & $0.019^{* * *}$ & $0.016^{* *}$ \\
Compulsory Education & {$[0.005]$} & {$[0.005]$} & {$[0.005]$} & {$[0.007]$} \\
No. of obs. & 3151 & 3151 & 3151 & 3057 \\
\hline Cohort FE & Yes & Yes & Yes & Yes \\
Municipality FE & Yes & Yes & Yes & Yes \\
Muni Controls & Yes & Yes & Yes & Yes \\
\hline
\end{tabular}

Notes: Each cell presents the coefficient for the treatment indicator from a separate regression. The units of analysis are municipality $\times$ birth-year cells. The human capital index is constructed using three measures: years of schooling, an indicator for having more than nine years of compulsory schooling, and the natural log of average wage income over all ages observable between 30 and 60 (see text for more details). See notes under Tables 4 and 5 for more details on specifications and controls in the baseline model.

Significance levels: ${ }^{*} \mathrm{p}<0.1 * * \mathrm{p}<0.05 * * * \mathrm{p}<0.01$ 
Appendix Table A.8: Robustness to Changes in Sample

\begin{tabular}{|c|c|c|c|c|}
\hline Outcome & $\begin{array}{c}(1) \\
\text { (Rural) } \\
\end{array}$ & $\begin{array}{c}(2) \\
(\text { Urban }) \\
\end{array}$ & $\begin{array}{c}(3) \\
\text { (No Always Impl.) } \\
\end{array}$ & $\begin{array}{c}(4) \\
(\text { Ever NHV) } \\
\end{array}$ \\
\hline Human Capital Index & $\begin{array}{c}0.030^{* *} \\
{[0.012]}\end{array}$ & $\begin{array}{l}0.021^{*} \\
{[0.012]}\end{array}$ & $\begin{array}{c}0.013 \\
{[0.008]}\end{array}$ & $\begin{array}{c}0.021^{* *} \\
{[0.009]}\end{array}$ \\
\hline No. of obs. & 1876 & 1986 & 3134 & 3331 \\
\hline Survival Past Age 65 & $\begin{array}{l}0.004^{*} \\
{[0.002]}\end{array}$ & $\begin{array}{c}0.007^{* *} \\
{[0.003]}\end{array}$ & $\begin{array}{c}0.007^{* * *} \\
{[0.002]}\end{array}$ & $\begin{array}{c}0.007^{* * *} \\
{[0.002]}\end{array}$ \\
\hline No. of obs. & 1876 & 1986 & 3134 & 3331 \\
\hline $\begin{array}{l}\text { Second Gen.: More than } \\
\text { Compulsory Education }\end{array}$ & $\begin{array}{c}0.018^{* * *} \\
{[0.006]}\end{array}$ & $\begin{array}{c}0.011 \\
{[0.008]}\end{array}$ & $\begin{array}{c}0.008 \\
{[0.005]}\end{array}$ & $\begin{array}{c}0.012^{* *} \\
{[0.005]}\end{array}$ \\
\hline No. of obs. & 1541 & 1610 & 1580 & 2728 \\
\hline $\begin{array}{l}\text { Cohort FE } \\
\text { Municipality FE } \\
\text { Muni Controls } \\
\text { Trends } \\
\text { County }\end{array}$ & $\begin{array}{l}\text { Yes } \\
\text { Yes } \\
\text { Yes }\end{array}$ & $\begin{array}{l}\text { Yes } \\
\text { Yes } \\
\text { Yes }\end{array}$ & $\begin{array}{l}\text { Yes } \\
\text { Yes } \\
\text { Yes }\end{array}$ & $\begin{array}{l}\text { Yes } \\
\text { Yes } \\
\text { Yes }\end{array}$ \\
\hline
\end{tabular}

Notes: Each cell presents the coefficient for the treatment indicator from a separate regression. The units of analysis are municipality $\times$ birth-year cells. The human capital index is constructed using three measures: years of schooling, an indicator for having more than nine years of compulsory schooling, and the natural $\log$ of average wage income over all ages observable between 30 and 60 (see text for more details). See notes under Tables 4 and 5 for more details on specifications and controls in the baseline model.

Significance levels: * $\mathrm{p}<0.1 * * \mathrm{p}<0.05^{* * *} \mathrm{p}<0.01$ 


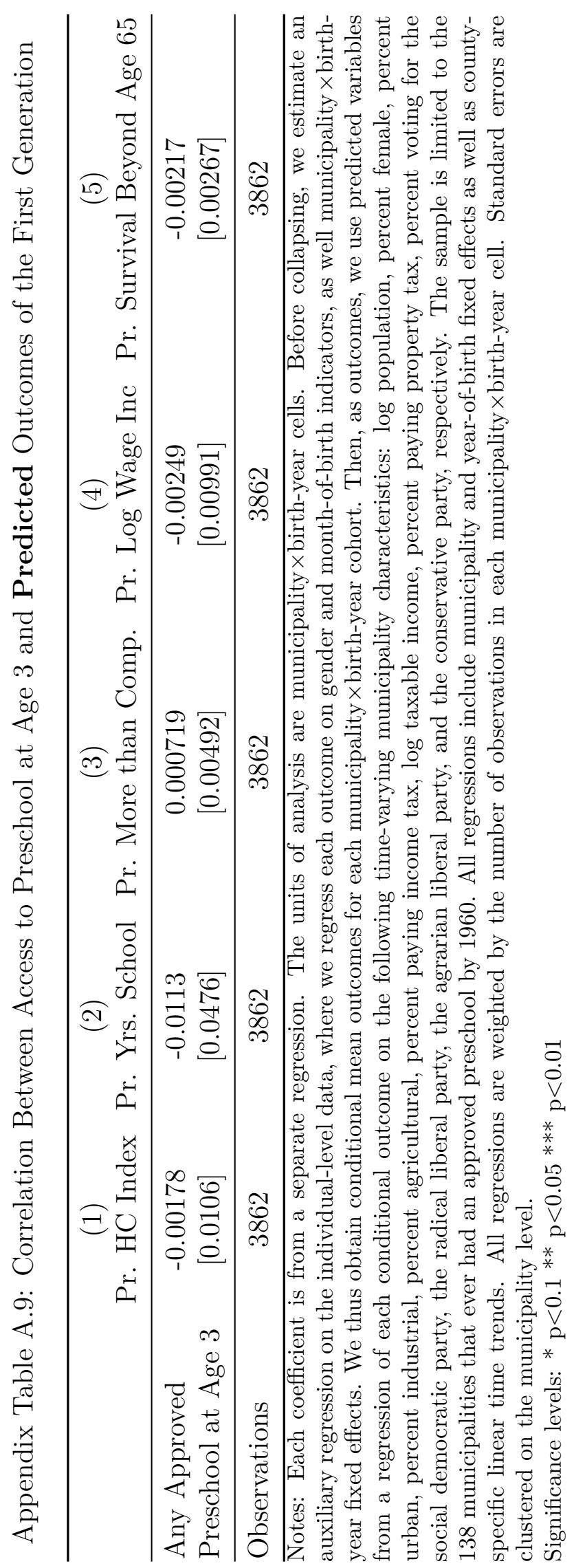


Appendix Table A.10: Correlation Between Access to Preschool at Age 3 and Predicted Outcomes of the Second Generation

\begin{tabular}{|c|c|c|c|}
\hline & $\begin{array}{c}(1) \\
\text { Yrs.School }\end{array}$ & $\begin{array}{c}(2) \\
\text { More than Comp. Edu. }\end{array}$ & $\begin{array}{c}(3) \\
\text { Gym. }\end{array}$ \\
\hline Any Approved & $-0.0190^{*}$ & -0.00179 & -0.00144 \\
\hline Preschool at Age 3 & {$[0.0104]$} & {$[0.00187]$} & {$[0.00164]$} \\
\hline Observations (cells) & 3156 & 3156 & 3156 \\
\hline
\end{tabular}

Appendix Table A.11: "First Stage": Access to Preschool and Share of Children Aged 3-6 Enrolled; 1939-1950; Urban Municipalities

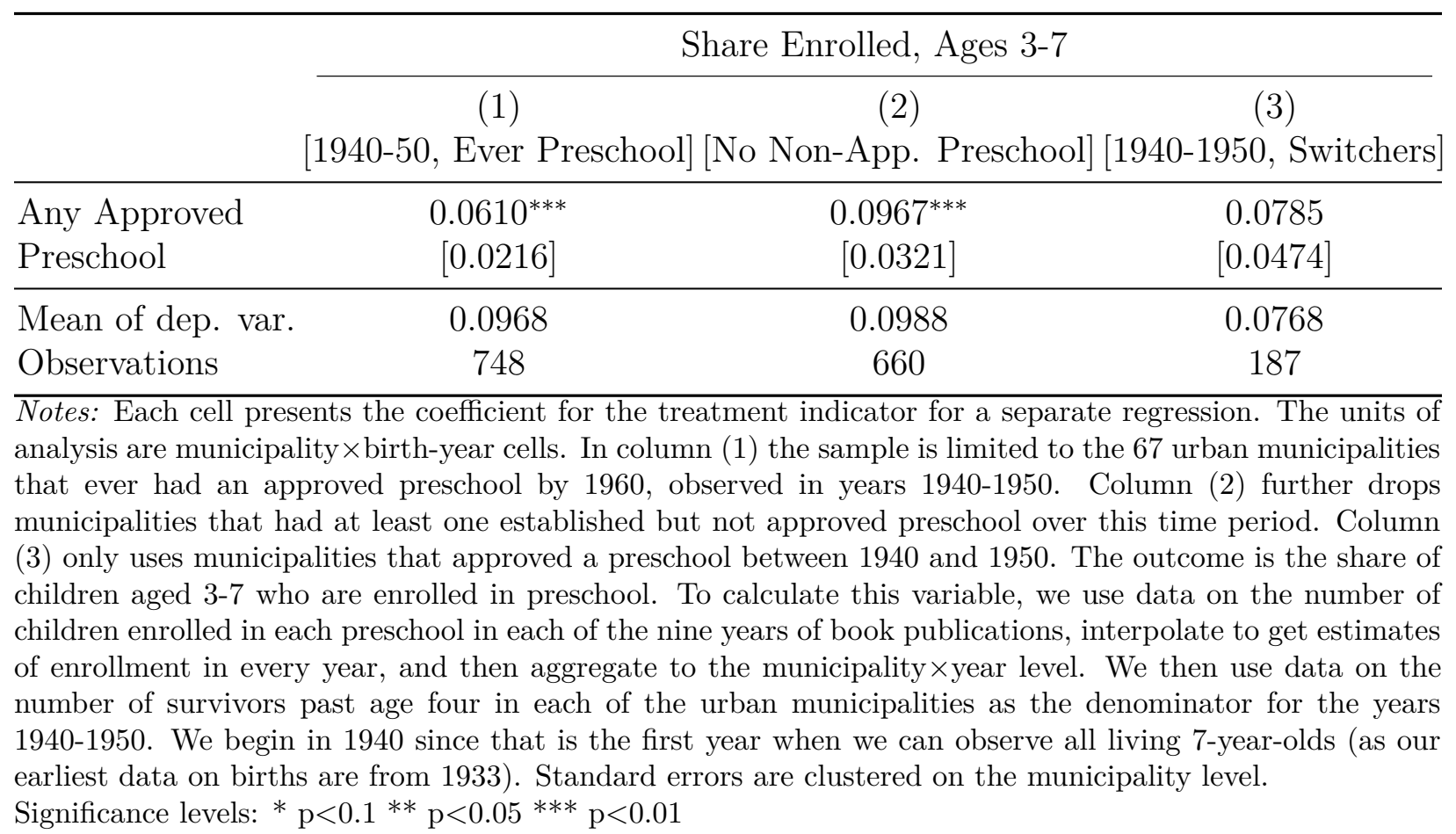


Appendix Table A.12: Interaction Effect between Access to NHV at Birth and Access to Preschool at Age 3 on a Human Capital Index and Survival; Drop Post-1949 Cohorts in 28 Municipalities with Worse NHV Data

(1)

Human Capital Index
(2)

Survival Past Age 65

\begin{tabular}{lcc}
\hline Any Approved & $0.026^{* * *}$ & $0.007^{* * *}$ \\
Preschool at Age 3 & {$[0.010]$} & {$[0.002]$} \\
NHV at Birth & $0.022^{* *}$ & $0.005^{*}$ \\
& {$[0.010]$} & {$[0.003]$} \\
Preschool x NHV & $-0.019^{* *}$ & -0.002 \\
& {$[0.010]$} & {$[0.003]$} \\
\hline Observations (cells) & 3638 & 3638
\end{tabular}

Notes: Each column reports the results from a separate regression. The units of analysis are municipality $\times$ birth-year cells. For the 28 municipalities that do not establish NHV by 1949 in our data, we drop cohorts born in 1950-1957 since we do not have precise information on NHV initiation in those years. See notes under Table 6 for more details on specifications and controls.

Significance levels: ${ }^{*} \mathrm{p}<0.1 * * \mathrm{p}<0.05 * * * \mathrm{p}<0.01$

Appendix Table A.13: Interaction Effects between Access to NHV at Birth and Access to Preschool at Age 3 on Education of the Next Generation

\begin{tabular}{lccc}
\hline & \multicolumn{3}{c}{ Child Outcomes at Age 25 } \\
\cline { 2 - 4 } & Yrs.School & More than Comp. Edu. & Gym. \\
\hline Any Approved & 0.0293 & $0.0110^{* *}$ & 0.00804 \\
Preschool at Age 3 & {$[0.0229]$} & {$[0.00541]$} & {$[0.00613]$} \\
NHV at Birth & 0.0110 & 0.00866 & 0.00665 \\
& {$[0.0305]$} & {$[0.00635]$} & {$[0.00752]$} \\
Preschool x NHV & -0.00813 & -0.00684 & -0.00373 \\
& {$[0.0268]$} & {$[0.00592]$} & {$[0.00755]$} \\
\hline Control Mean, dep. var. & 12.22 & 0.747 & 0.216 \\
Observations (cells) & 3151 & 3151 & 3151 \\
\hline
\end{tabular}

Notes: Each column reports the results from a separate regression. The units of analysis are cells based on the mother's municipality $\times$ birth-year. See notes under Table 6 for more details on specifications and controls.

Significance levels: ${ }^{*} \mathrm{p}<0.1 * * \mathrm{p}<0.05 * * * \mathrm{p}<0.01$ 
Appendix Table A.14: Interaction Effect between Access to NHV at Birth and Access to Preschool at Age 3 on Education, Income, and Survival; Drop NHV-Treated Observations at Bottom of Human Capital Index Distribution

\begin{tabular}{lcc}
\hline & $(1)$ & $(2)$ \\
& Human Capital Index & Survival Past Age 65 \\
\hline Any Approved & $0.028^{* * *}$ & $0.007^{* * *}$ \\
Preschool at Age 3 & {$[0.010]$} & {$[0.002]$} \\
NHV at Birth & $0.024^{* *}$ & $0.005^{*}$ \\
& {$[0.010]$} & {$[0.003]$} \\
Preschool x NHV & $-0.021^{* *}$ & -0.002 \\
& {$[0.010]$} & {$[0.003]$} \\
\hline Observations (cells) & 3862 & 3862 \\
\hline Notes: Each column reports the results from a separate regression. & The units of analysis are \\
municipality $\times$ birth-year cells. Before collapsing the data, we drop NHV-treated individual observations \\
who are in the 1st percentile of the human capital index distribution. See notes under Table 6 for more \\
details on specifications and controls.
\end{tabular}




\section{B The Nurse Home Visiting Program, Prior Evidence, and Main Effects in the Preschool Analysis Sample}

The Danish Nurse Home Visiting Program was first introduced in 1937 and still exists today. From that year onwards, NHV was gradually rolled out in Danish municipalities until it became a compulsory municipal program in 1974. Earlier work has studied the short- and long-run health effects of access to NHV in the 1937-1949 period (Wüst, 2012; Hjort et al., 2017; Wüst et al., 2018). Similar to the approach in this paper, these studies have exploited the rollout of NHV over time in a difference-in-difference framework.

Figure B.1 displays the geographic and time variation in NHV availability for Danish municipalities in the 1937-1949 period. The figure is based on data on program initiation dates for all implementing municipalities of that period from the Danish National Archives. The displayed variation in the timing of program implementation across municipalities largely stemmed from the lengthy accreditation process at the DNBH: The DNBH both approved the content of municipal programs and the planned number of nurses (to secure adequate coverage in the local programs). Accreditation was a prerequisite for government 50 percent co-funding of municipal programs. Another source of variation came from differences in the preferences of local general practitioners, who in some places promoted the initiation of NHV but in other places opposed it (Buus, 2001).

Exploiting the variation in NHV access across time and municipalities, Wüst (2012) shows that - in the short run - the program reduced infant mortality. The study finds that program exposure led to a significant increase in infant survival of 5-8 lives saved per 1,000 live births. In supplementary analyses, she finds that this mortality decline is particularly driven by a decrease in deaths from diarrhea-related causes decreased; in fact, NHV accounted for 17-29 percent of the overall decrease in diarrhea-related mortality over the analysis time period. She argues that a primary mechanism for this effect was through improved infant nutrition (e.g., via breastfeeding) and a reduction in the severity of illness due to better monitoring by health professionals.

In a follow-up paper, Hjort et al. (2017) find that NHV also had positive long-run health effects: Exposed individuals have higher long-run survival rates in adulthood (in the 45-64 year age range that they can study) and are less likely to be diagnosed with cardiovascular disease. Moreover, NHV-treated cohorts have fewer hospital nights during the same range of ages. While the effects for health outcomes are sizeable and robust, estimates for the impact of NHV on education and labor market outcomes (years of schooling, an indicator for only completing compulsory education, log wages and occupational status around age $60)$ are small, imprecise, and unstable across specifications. 
Appendix Figure B.1: The Year of NHV Implementation Across Danish Municipalities, 1937-1949

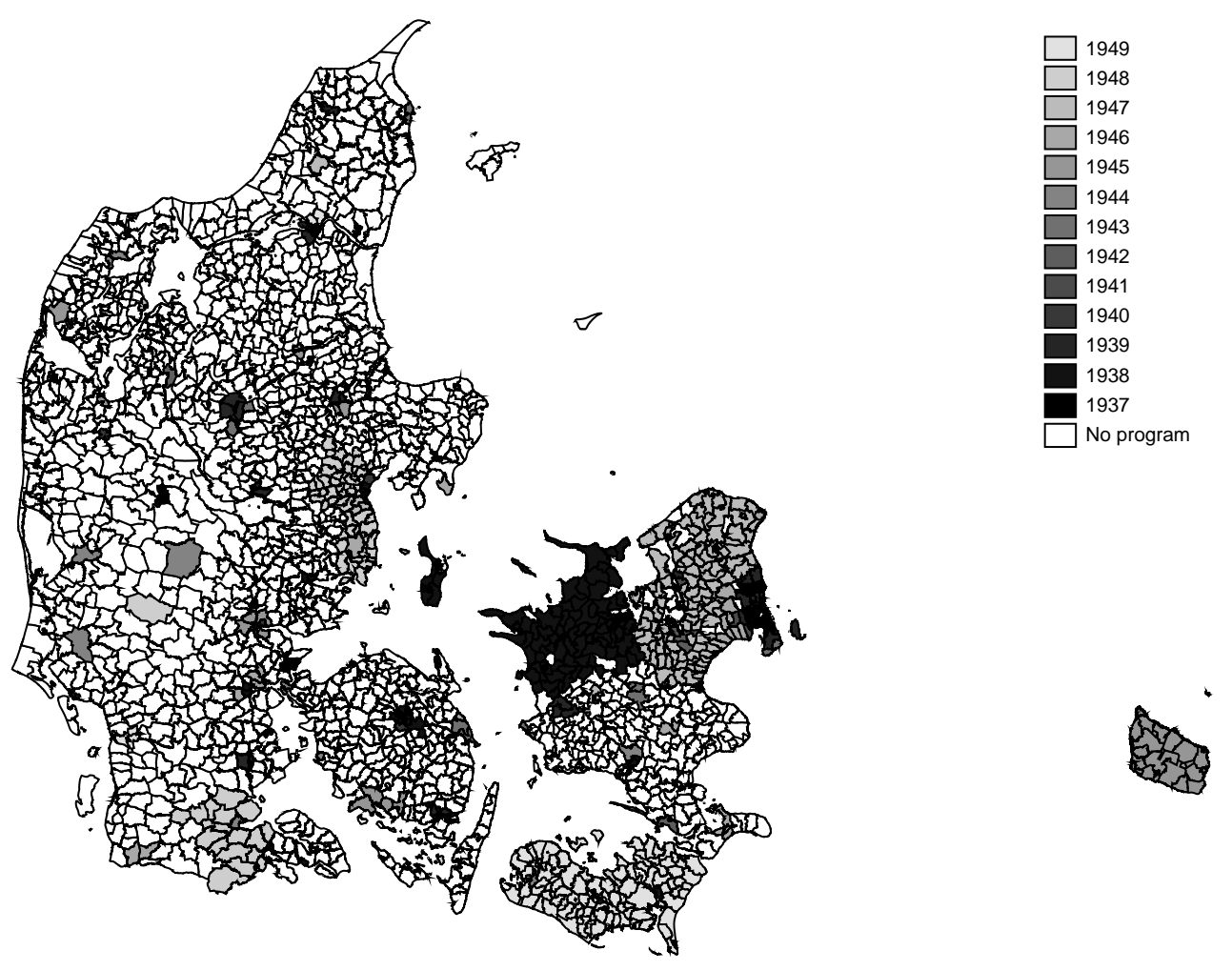

Source: Hjort et al. (2017).

Finally, bridging the gap between short- and long-run impacts of NHV, Wüst et al. (2018) analyze young adult outcomes using a similar research design. They do not find any significant impacts of NHV on male obesity status and height at conscription (at age 18-25). However, at this young age, obesity rates are still very low in the population of men that they study. At the same time, they document that treated men were more likely to emigrate from Denmark. Given that they show that emigrants in the sample are positively selected and given that individuals who emigrated before 1980 do not enter the analyses in Hjort et al. (2017), this finding suggests that the results of Hjort et al. (2017) may be lower bounds for the overall effects of NHV.

The main threat to identification in the studies on NHV exposure is endogenous program adoption. Hjort et al. (2017) provide two pieces of evidence in support of their empirical strategy: First, they show that their main results are robust to different specifications (i.e., the inclusion of trends and time-varying controls) and constraints to the analysis sample of municipalities (i.e., a focus on "ever-implementers" and a matched sample of treated and control municipalities). Second, they present event-study graphs that support the credibility 
of the parallel trend assumption.

In light of the previous work on NHV in Denmark, we do not focus on the main effects of NHV in this paper. However, the following tables reproduce the findings in Hjort et al. (2017) using our main analysis sample. As Appendix Tables B.1 and B.2 show, we find similar effects of NHV exposure on survival (not always precise), the number of nights spent in the hospital, and on the incidence of diagnoses for cardiovascular diseases and heart conditions in our preschool analysis sample. Additionally, Appendix Tables B.3 and B.4 confirm that the main effects of preschool and NHV exposure are largely unaffected by the inclusion of an indicator for exposure to the other program. This finding lends further credibility to our assumption of independence of the introduction of the two municipally-organized programs. 
Appendix Table B.1: Effect of NHV on Survival in Preschool Analysis Sample

\begin{tabular}{lcc}
\hline Outcome & $(1)$ & $(2)$ \\
\hline Survival beyond Age 55 & $0.002^{*}$ & $0.001^{*}$ \\
& $(0.001)$ & $(0.001)$ \\
Control Mean, dep. var. & 0.973 & 0.973 \\
No. of obs. & 3862 & 3862 \\
\hline Survival beyond Age 60 & $0.002^{*}$ & 0.002 \\
& $(0.001)$ & $(0.001)$ \\
Control Mean, dep. var. & 0.932 & 0.932 \\
No. of obs. & 3862 & 3862 \\
\hline Survival beyond Age 65 & 0.003 & 0.003 \\
& $(0.002)$ & $(0.002)$ \\
Control Mean, dep. var. & 0.875 & 0.875 \\
No. of obs. & 3862 & 3862 \\
\hline Cohort FE & Yes & Yes \\
Municipality FE & Yes & Yes \\
Muni Controls & Yes & Yes \\
County Trends & No & Yes \\
\hline
\end{tabular}

Notes: Each cell presents the coefficient for the treatment indicator - which is equal to 1 if the NHV program was operating in a given municipality $\times$ birth-year and 0 otherwise - for a separate regression. The units of analysis are municipality $\times$ birth-year cells. Before collapsing, we estimate an auxiliary regression on the individual-level data, where we regress each outcome on gender and monthof-birth indicators, as well municipality $\times$ birth-year fixed effects. We thus obtain conditional mean outcomes for each municipality $\times$ birth-year cohort, and use them as dependent variables. The sample is limited to the $138 \mathrm{mu}-$ nicipalities that ever had an approved preschool by 1960 . All regressions are weighted by the number of observations in each municipality $\times$ birth-year cell. Standard errors are clustered on the municipality level.

Significance levels: $* \mathrm{p}<0.1 * * \mathrm{p}<0.05 * * * \mathrm{p}<0.01$ 
Appendix Table B.2: Effect of NHV on Long-Term Health Outcomes in Preschool Analysis Sample

\begin{tabular}{lcc}
\hline Outcome & $(1)$ & $(2)$ \\
\hline Hosp. Nights: Age 55-64 & $-0.274^{*}$ & -0.252 \\
& $(0.150)$ & $(0.164)$ \\
Control Mean, dep. var. & 12.415 & 12.415 \\
No. of obs. & 3862 & 3862 \\
\hline Diagnosed Cardio & $-0.006^{* *}$ & $-0.006^{* *}$ \\
& $(0.002)$ & $(0.002)$ \\
Control Mean, dep. var. & 0.220 & 0.220 \\
No. of obs. & 3862 & 3862 \\
\hline & $-0.003^{* *}$ & $-0.003^{* *}$ \\
Diagnosed Heart & $(0.001)$ & $(0.001)$ \\
Control Mean, dep. var. & 0.074 & 0.074 \\
No. of obs. & 3862 & 3862 \\
\hline Diagnosed Diabetes & -0.001 & -0.001 \\
Control Mean, dep. var. & $(0.001)$ & $(0.001)$ \\
No. of obs. & 0.031 & 0.031 \\
\hline Diagnosed Cancer & 3862 & 3862 \\
\hline Control Mean, dep. var. & -0.000 & -0.000 \\
No. of obs. & $(0.001)$ & $(0.001)$ \\
\hline Cohort FE & 0.043 & 0.043 \\
Municipality FE & 3862 & 3862 \\
Muni Controls & Yes & Yes \\
County Trends & Yes & Yes \\
\hline Yoss Ses & No & Yes \\
\hline
\end{tabular}

Notes: See notes under Appendix Table B.1.

Significance levels: ${ }^{*} \mathrm{p}<0.1 * * \mathrm{p}<0.05 * * * \mathrm{p}<0.01$ 
Appendix Table B.3: Main Effects of Access to Preschool and to NHV on Human Capital Index and Survival

\begin{tabular}{lcc}
\hline Outcome/Program & $(1)$ & $(2)$ \\
\hline Human capital index: Preschool & $0.046^{* * *}$ & $0.024^{* * *}$ \\
& $(0.010)$ & $(0.009)$ \\
Human capital index: NHV & -0.001 & 0.005 \\
& $(0.007)$ & $(0.006)$ \\
No. of obs. & 3862 & 3862 \\
\hline Survival beyond Age 65: Preschool & $0.005^{* *}$ & $0.007^{* * *}$ \\
& $(0.002)$ & $(0.002)$ \\
Survival beyond Age 65: NHV & 0.003 & 0.003 \\
& $(0.002)$ & $(0.002)$ \\
Control Mean, dep. var. & 0.875 & 0.875 \\
No. of obs. & 3862 & 3862 \\
\hline Cohort FE & Yes & Yes \\
Municipality FE & Yes & Yes \\
Muni Controls & Yes & Yes \\
County Trends & No & Yes \\
\hline
\end{tabular}

Notes: See notes under Appendix Table B.1.

Significance levels: * $\mathrm{p}<0.1{ }^{* *} \mathrm{p}<0.05 * * * \mathrm{p}<0.01$ 
Appendix Table B.4: Main Effects of Access to Preschool and to NHV on Long-Term Health Outcomes

\begin{tabular}{lcc}
\hline Outcome/Program & $(1)$ & $(2)$ \\
\hline Hosp. Nights: Age 55-64: Preschool & $-0.385^{* *}$ & $-0.389^{*}$ \\
& $(0.192)$ & $(0.201)$ \\
Hosp. Nights: Age 55-64: NHV & $-0.277^{*}$ & -0.250 \\
& $(0.148)$ & $(0.162)$ \\
Control Mean, dep. var. & 12.415 & 12.415 \\
No. of obs. & 3862 & 3862 \\
\hline Diagnosed Cardio: Preschool & 0.002 & 0.002 \\
& $(0.003)$ & $(0.003)$ \\
Diagnosed Cardio: NHV & $-0.006^{* *}$ & $-0.006^{* *}$ \\
& $(0.002)$ & $(0.002)$ \\
Control Mean, dep. var. & 0.220 & 0.220 \\
No. of obs. & 3862 & 3862 \\
\hline Diagnosed Heart: Preschool & -0.001 & -0.001 \\
& $(0.002)$ & $(0.002)$ \\
Diagnosed Heart: NHV & $-0.003^{* *}$ & $-0.003^{* *}$ \\
& $(0.001)$ & $(0.001)$ \\
Control Mean, dep. var. & 0.074 & 0.074 \\
No. of obs. & 3862 & 3862 \\
\hline Diagnosed Diabetes: Preschool & -0.001 & -0.001 \\
& $(0.001)$ & $(0.001)$ \\
Diagnosed Diabetes: NHV & -0.001 & -0.001 \\
& $(0.001)$ & $(0.001)$ \\
Control Mean, dep. var. & 0.031 & 0.031 \\
No. of obs. & 3862 & 3862 \\
\hline Diagnosed Cancer: Preschool & -0.001 & -0.000 \\
& $(0.001)$ & $(0.001)$ \\
Diagnosed Cancer: NHV & -0.000 & -0.000 \\
& $(0.001)$ & $(0.001)$ \\
Control Mean, dep. var. & 0.043 & 0.043 \\
No. of obs. & 3862 & 3862 \\
\hline Cohort FE & Yes & Yes \\
Municipality FE & Yes & Yes \\
Muni Controls & Yes & Yes \\
County Trends & No & Yes \\
\hline & & \\
Dote: Sec nts & & \\
& &
\end{tabular}

Notes: See notes under Appendix Table B.1.

Significance levels: ${ }^{*} \mathrm{p}<0.1{ }^{* *} \mathrm{p}<0.05^{* * *} \mathrm{p}<0.01$ 


\section{Sample Construction and Missing Individuals}

Since we can only study the outcomes of survivors, who are observed in the administrative data - i.e., those who were aged 23 to 50 in 1980 - we are concerned with endogenous sample selection due to effects on mortality or emigration before 1980. We address this concern in two ways. First, we compare our analysis sample to annual aggregate data on live births and infant deaths in Denmark, which is available for years 1933-1950. Appendix Figure C.1 illustrates the percentage of "missing" Danish-born individuals in our outcome data (including individuals who are missing due to invalid parish codes) by year of birth. ${ }^{28}$

Appendix Figure C.1: Comparison of First-Year Survivors to All Danish-Born Individuals in the Outcome Data

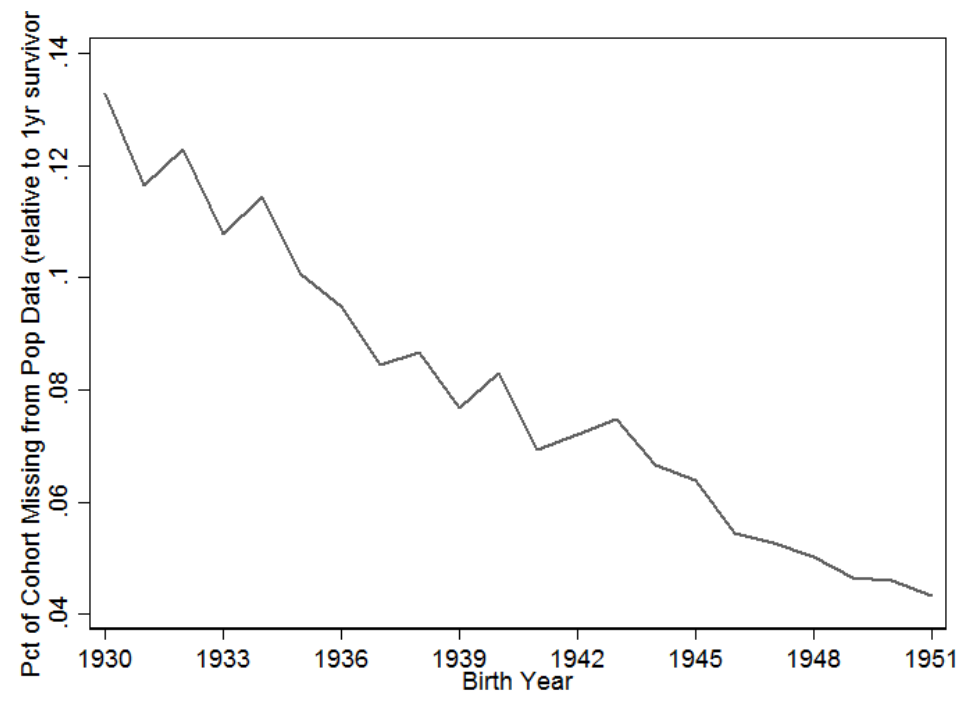

Notes: This graph shows the percentage of "missing" Danish-born individuals in our outcome data (including individuals who are missing due to invalid parish codes) by year of birth. We calculate this percentage as: (\# of Danish-born observations in register data)/(\# of live births - \# infant deaths).

Not surprisingly, we miss more individuals from older than younger cohorts - about 13 percent of the 1930 cohort and only 4 percent of the 1951 cohort are missing from our outcome data. However, using only the younger cohorts with fewer missing observations, we found that statistically significant mortality impacts of preschool only materialize around age 60. Thus we do not believe that selection due to mortality prior to age 50 has a meaningful impact on our results.

Second, we use municipality-level data on live births and infant deaths for 67 urban municipalities in the ever-implementing sample for years 1933-1950. We correlate the share

\footnotetext{
${ }^{28}$ We calculate this percentage as: (\# of Danish-born observations in register data)/(\# of live births - \# infant deaths). Aggregate data on live births and infant deaths come from DNBH (various years).
} 
of "not missing" Danish-born individuals in our outcome data relative to all first-year survivors with our key treatment variable, an indicator for an approved preschool in the municipality $\times$ year. Appendix Table C.1 reports the results from various specifications of this regression, showing no statistically significant relationships.

Appendix Table C.1: Correlation between Share of Cohort "Not Missing" and Access to Preschool; Urban Municipalities

\begin{tabular}{lccc}
\hline Outcome & $(1)$ & $(2)$ & $(3)$ \\
\hline Any Approved Preschool at Age 3 & -0.070 & -0.015 & 0.111 \\
& $(0.160)$ & $(0.092)$ & $(0.084)$ \\
Mean of dep. var. & & 0.928 & \\
No. of obs. & & 1548 & \\
\hline Cohort FE & Yes & Yes & Yes \\
Municipality FE & Yes & Yes & Yes \\
Muni Controls & No & Yes & Yes \\
County Trends & No & No & Yes \\
\hline
\end{tabular}

Notes: Each cell presents the coefficient for the treatment indicator for a separate regression. The units of analysis are municipality $\times$ birth-year cells. The sample is limited to the 67 urban municipalities that ever had an approved preschool by 1960. The outcome is the ratio of observations in our outcome data to the number of 1-year survivors (i.e., \# of live births - \# infant deaths) in each municipality $\times$ year cell. All regressions are weighted by the number of observations in each municipality $\times$ birth-year cell. Standard errors are clustered on the municipality level.

Significance levels: ${ }^{*} \mathrm{p}<0.1{ }^{* *} \mathrm{p}<0.05^{* * *} \mathrm{p}<0.01$ 